Article

\title{
Bidirectional Piezoelectric Energy Harvester
}

\author{
Andrius Čeponis ${ }^{1, *}$, Dalius Mažeika ${ }^{2}$ and Artūras Kilikevičius ${ }^{3}$ (i) \\ 1 Department of Engineering Graphics, Faculty of Fundament Sciences, Vilnius Gediminas Technical \\ University, Sauletekio avn., 11, LT-10223 Vilnius, Lithuania \\ 2 Department of Information Systems, Faculty of Fundament Sciences, Vilnius Gediminas Technical \\ University, Sauletekio avn., 11, LT-10223 Vilnius, Lithuania \\ 3 Institute of Mechanical Science, Vilnius Gediminas Technical University, J. Basanaviciaus str. 28, \\ LT-03224 Vilnius, Lithuania \\ * Correspondence: andrius.ceponis@vgtu.lt; Tel.: +37-062-214-611
}

Received: 1 August 2019; Accepted: 3 September 2019; Published: 6 September 2019

\begin{abstract}
This paper represents a numerical and experimental investigation of the bidirectional piezoelectric energy harvester. The harvester can harvest energy from the vibrating base in two perpendicular directions. The introduced harvester consists of two cantilevers that are connected by a particular angle and two seismic masses. The first mass is placed at a free end of the harvester while the second mass is fixed at the joining point of the cantilevers. The piezoelectric energy harvester employs the first and the second out of plane bending modes. The numerical investigation was carried out to obtain optimal geometrical parameters and to calculate the mechanical and electrical characteristics of the harvester. The energy harvester can provide stable output power during harmonic and impact-based excitation in two directions. The results of the investigations showed that energy harvester provides a maximum output power of $16.85 \mu \mathrm{W}$ and $15.94 \mu \mathrm{W}$ when the base has harmonic vibrations in $y$ and $z$ directions, respectively. Maximum output of $4.059 \mathrm{nW} / \mathrm{N}$ and $3.1 \mathrm{nW} / \mathrm{N}$ in $y$ and $z$ directions were obtained in case of impact based excitation
\end{abstract}

Keywords: energy harvesting; bidirectional excitation; cantilever array

\section{Introduction}

Nowadays, wireless electronic devices, networks of wireless sensors, biomedical devices, and wearable electronics take a huge part in most areas of industry, life sciences, medicine, etc. [1,2]. However, wireless and portable devices have the main disadvantage-short battery life, and as a result, it leads to environment pollution, high costs of maintenance and etc. Fortunately, nowadays, conventional batteries can be replaced partly or fully by kinetic energy harvesters $[3,4]$. There exist four main kinetic energy harvesting mechanism: electromagnetic, electrostatic, triboelectric, and piezoelectric. Each kinetic energy transduction mechanism has disadvantages like electromagnetic kinetic energy harvesters have low-level output voltage, are not suitable for high excitation frequencies and are not suitable for MEMS applications. Electrostatic energy harvesters have demand on external power supply, extremely high isolation ratio, and have a complex structure. Triboelectric energy harvesters provide low-level electrical characteristics which are, in most cases, not suitable for direct delivery to load [5-8]. On the other hand, energy harvesters based on piezoelectric materials have numerous advantages like high output power densities, piezoelectric energy harvesters are suitable for MEMS applications, in most cases, harvesters are magnetic field free and have a simple structure and etc. $[9,10]$. Therefore, due to these advantages, piezoelectric energy harvesters attracted a lot of attention during the last decade. Usually, investigations of piezoelectric energy harvesters are focused on the improvement of mechanical and electric characteristics of piezoelectric cantilevers. Disadvantages like narrow bandwidth and uneven strain distribution at piezoelectric material have 
been investigated extensively. However, can be noticed, that in most cases, the excitation force vector is perpendicular to the harvesters mounting plane [11-13]. In real-life applications, energy harvester designed to operate with ideally aligned excitation force can face operation issues due to dynamic changes in the direction of excitation force. Therefore, investigations on piezoelectric energy harvesters which operation is based on bidirectional excitation force become highly relevant to obtain possibility employ energy harvesters at real environments with the varying direction of excitation.

Fan and et al. reported on multipurpose piezoelectric energy harvester. The harvester is based on beam-roller structure which is able to operate with sway and bidirectional excitation forces. Proposed harvester has a simple structure which is based on the cylinder, piezoelectric cantilever with magnetic coupling and clamping frame. Operation of the harvester is based on the first bending mode of the cantilever. Authors claimed that such structure can harvest kinetic energy from two perpendicular excitation forces at the same time. Also, the proposed structure exhibits frequency up functionality i.e., converts low-frequency sway vibrations to higher frequency vibrations suitable to drive piezoelectric cantilever [14].

Mei and Li reported on cylindrical double-wall multi-modal piezoelectric energy harvester for multi-directional energy harvesting. The design of harvester is based on two steel hollowed cylinders placed inside each other and seismic mass. The active material is located on the outer surface of the inner cylinder. Operation of the harvester is based on eight vibration modes. Therefore, multidirectional operation of the energy harvester is obtained by the employment of different vibrations modes which have differed deformation directions. However, the design of cantilever has the main disadvantage, i.e., low strain amplitudes and its distribution across active material due to the high stiffness of cylinders [15].

Yang and et al. investigated frame based two-directional piezoelectric energy harvester. The energy harvester is based on three cantilevers connected to $U$ shaped frame and seismic mass placed in the center of the horizontal cantilever. Operation of the energy harvesting structure is based on two fundamental vibration modes, i.e., vertical and horizontal. On basis of numerical and experimental investigations, the authors concluded that that proposed energy harvester could capture vibration energy from arbitrary directions in a 2D plane. Also, the authors claimed that if structural parameters of the harvester are well adjusted, the system can provide a suitable power output level for practical applications [16].

Wang and et al. introduced a two-directional energy harvester with the ability to harvest kinetic energy in two in-plane directions using a flexible cylinder with radially distributed piezoelectric patches. The harvester has simple design i.e., fixed end cylinder made of polyurethane, four piezoelectric patches which are placed near the fixed end of the cylinder. Based on numerical and experimental investigations, the authors concluded that the proposed design of energy harvester could harvest vibration energy in the arbitrary in-plane direction and provide stable power output irrespective to angle of excitation force vector. Also, the authors introduced a new approach named angle bandwidth. This approach gives the possibility to describe harvester's ability to harvest bidirectional vibration energy [17].

Karami and Inman reported on modeling and experimental investigations of the zig-zag shaped energy harvester. The harvester contains a collection of cantilevers, with rectangular cross-sections, placed next to each other on the main plane. Each cantilever is connected to the neighboring cantilever and can have out-of-plane vibrations and to twist. Based on the investigations it can be assumed that energy harvester can capture bidirectional vibrations of two vibration modes. However, the authors did not investigate harvester's ability to harvest bidirectional vibrations [18,19].

Abdelmoula and et.al. investigated zig-zag shaped piezoelectric energy harvester as well. The design of harvester is similar to introduced by Karami and Inman $[18,19]$. The authors investigated harvesters ability to harvest the energy of torsion deformations and compered obtained results with bending mode. In conclusion, the authors stated that the torsion deformation mode is more effective compared to the bending mode. Based on numerical and experimental investigations it can be assumed that proposed energy harvester can be used to harvest bidirectional vibrations by torsional and bending modes. However, the authors do not mention an intention to investigate bidirectional operation principle [20]. 
This paper introduces numerical and experimental investigations on bidirectional energy harvester. To obtain suitable geometrical parameters of the harvester, the multiparametric problem with six geometrical variables has been solved. Further, the electrical and mechanical characteristics of the harvester have been investigated in detail. Results of the investigations revealed that the proposed design of the energy harvester can provide stable power output during bidirectional harmonic and impact based excitations.

\section{Design and Operation of Bidirectional Energy Harvester}

The proposed energy harvester consists of two bimorph piezoelectric cantilevers that are connected by angle $\alpha_{2}$ (Figure 1(1,2)). The lower cantilever is rigidly clamped to the base under angle $\alpha_{1}$. Specific angles give possibility to increase rotation moment when bidirectional vibrations are used. Two seismic masses are included in order to increase rotation moment and to decrease resonant frequencies of the harvester (Figure 1(3,4)). The first seismic mass $\mathrm{M}_{1}$ is placed at the junction between two cantilevers while the second seismic mass $\mathrm{M}_{2}$ is fixed at the free end of the structure.

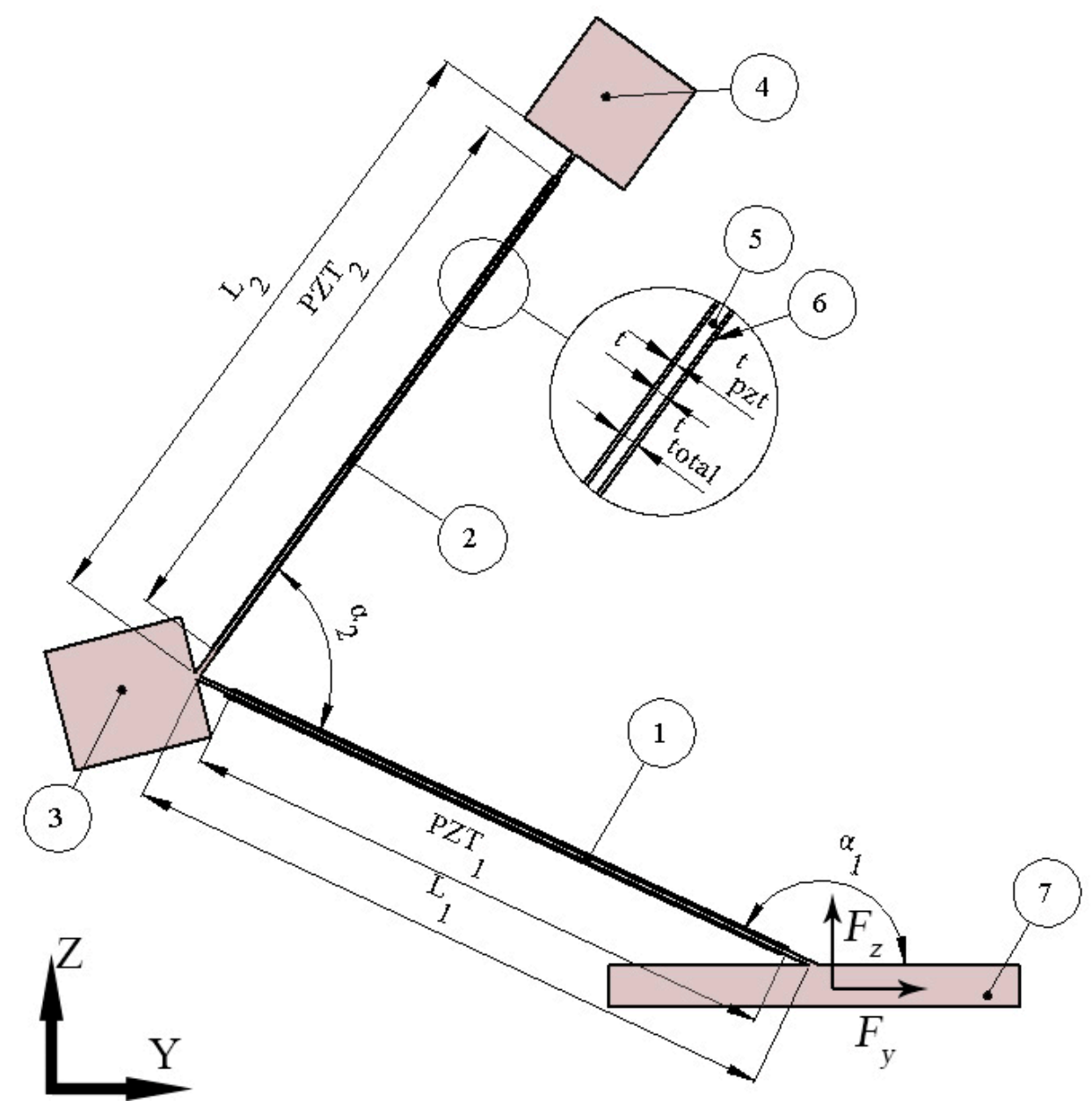

Figure 1. Schematics of bidirectional energy harvester; 1,2 - the first and second cantilever, respectively; 3,4-seismic masses, $\mathrm{M}_{1}$ and $\mathrm{M}_{2}$, respectively; 5-body of the harvester; 6-piezoelectric material made of PIC255 piezo ceramics; 7-clamping base.

All geometrical and physical parameters of the piezoelectric energy harvester are listed in Tables 1 and 2. The geometrical parameters were obtained by solving multiparametric optimization problem with six design variables. The optimization problem is described in Section 3. The initial values of the harvester used for optimization are listed in Table 3. 
Table 1. Material properties.

\begin{tabular}{ccc}
\hline Material Properties & Aluminum Alloy 6061 & Piezo Ceramic PIC255 \\
\hline Density $\left[\mathrm{kg} / \mathrm{m}^{3}\right]$ & 2700 & 7800 \\
\hline Young's modulus $\left[\mathrm{N} / \mathrm{m}^{2}\right]$ & $6.89 \times 10^{10}$ & - \\
\hline Poisson's ratio & 0.33 & - \\
\hline Isotropic structural loss factor & 0.02 & 0.015 \\
\hline Relative permittivity & - & $\begin{array}{c}\text { In the polarization direction } \varepsilon_{33}{ }^{\mathrm{T}} / \varepsilon_{0}=1200 ; \\
\text { Perpendicular to polarity } \varepsilon_{11}{ }^{\mathrm{T}} / \varepsilon_{0}=1500\end{array}$ \\
\hline Elastic stiffness coefficient $\mathrm{c}_{33} \mathrm{D},\left[\mathrm{N} / \mathrm{m}^{2}\right]$ & - & $16.6 \times 10^{10}$ \\
\hline Dielectric loss factor- $\tan \delta\left[10^{-3}\right]$ & - & 20 \\
\hline Coupling factor $\mathrm{k}_{31}$ & - & 0.35 \\
\hline Piezoelectric voltage coefficient $\mathrm{g}_{31}$ & - & -11.3 \\
\hline $\left.10^{-3} \mathrm{Vm} / \mathrm{N}\right]$
\end{tabular}

Operation of the energy harvester is based on the first and second out of plane bending modes of the structure. The energy harvesters are able to harvest energy when external force is applied to the base in $z$ or $y$ directions. The harvester operates as a spring with two masses attached by lever arms when vibration force is applied in $z$ direction. Misbalance of the system is created by seismic masses, specific angles $\alpha_{1}$ and $\alpha_{2}$. Such design of the harvester allows to increase rotation moment which leads to improved electrical characteristics by increased strain distribution.

When external force is acting in $y$ direction then energy harvester can be described as the spring with additional seismic massed attached to it by lever arms and effected by force perpendicular to axis of the spring. In both excitation cases the first and second out of plane bending modes are obtained and rotation moments are increased because of seismic masses and specific angles $\alpha_{1}$ and $\alpha_{2}$ that increase bending strain at piezo ceramic layers.

Also, it must be mentioned that cantilever $\mathrm{L}_{2}$ can operate as a dynamic vibration damper (DVA) for cantilever $L_{1}$. Numerous reports of DVA applications in piezoelectric energy harvesters can be found [20-22]. Operation of cantilever $\mathrm{L}_{2}$ as DVA is avoidable for the proposed energy harvester, therefore, it was controlled that proper geometrical parameters of cantilevers would not be selected during the numerical investigation.

\section{Results of Numerical Investigation}

Numerical investigation of bidirectional energy harvester was performed in order to solve the following tasks: To obtain optimal geometrical parameters of the harvester by solving optimization problem, indicate the highest possible excitation acceleration amplitude, verify operation principle of the harvester and to calculate mechanical and electrical output characteristics. For this purpose, finite elements model (FEM) was built by employing Comsol 5.4 software. Structure of the harvester was made from aluminum 6061 alloy while PIC225 soft piezoelectric ceramic (Physik Instrumente GmbH, Germany) was used for piezo ceramic elements. Material properties are presented in Table 1.

Initial values of the parameters used for the optimization of the bidirectional energy harvester were set up (Table 2). Modal analysis of the harvester was performed to find modal shapes and natural frequencies when initial values are used. The results are shown in Figure 2.

Table 2. The initial values of the parameters used for optimization.

\begin{tabular}{cc}
\hline Parameter & Value \\
\hline $\mathrm{L}_{\min }$ & $75 \mathrm{~mm}$ \\
\hline $\mathrm{M}_{\min }$ & $3 \mathrm{~g}$ \\
\hline$\alpha_{\min }$ & $1.13 \mathrm{rad}$ \\
\hline
\end{tabular}


(a)

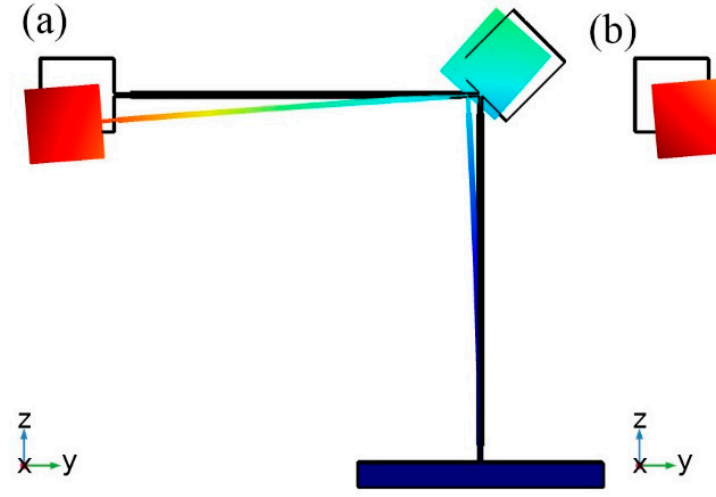

(b)

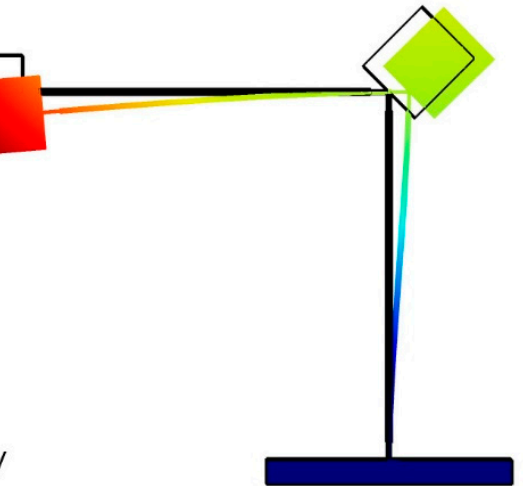

Figure 2. Vibration modes of the harvester with initial parameters; (a) - modal shape at $29.858 \mathrm{~Hz}$; (b) -modal shape at $41.257 \mathrm{~Hz}$.

The first and second bending modes are the most suitable for bidirectional operation, therefore, optimization of the harvester will be performed with aim employ these modes for bidirectional energy harvesting.

Optimization problem has been divided into three steps. These steps were performed sequentially, applying frequency-domain study when the acceleration of the base was aligned to the $z$ and $y$-axis. The excitation frequency range was analyzed from $10 \mathrm{~Hz}$ to $100 \mathrm{~Hz}$. Acceleration amplitude of the base was set to $0.1 \mathrm{~m} / \mathrm{s}^{2}$.

The length of cantilevers $L_{1}$ and $L_{2}$ were optimized in the first step. Seismic masses $\left(M_{1}\right.$ and $\left.M_{2}\right)$ and angles $\left(\alpha_{1}\right.$ and $\left.\alpha_{2}\right)$ were set to initial values which are given in Table 2. Maximization of average von Mises stress along both cantilevers was chosen as an objective of the optimization problem:

$$
\max _{l}\left(\sigma_{\operatorname{avg}}(l)\right)
$$

subjected to

$$
\begin{gathered}
L_{\min } \leq L_{i} \leq L_{\max } \\
\sigma_{a v g}<\sigma_{t}
\end{gathered}
$$

where

$$
l=\left(L_{1}, L_{2}\right)
$$

here $\sigma_{\text {avg }}$ average stress inducted along the cantilevers; $\sigma_{t}$ tensile strength of 6061 aluminum alloy; $L_{1}$ and $L_{2}$ are length of the cantilevers; $L_{\min }$ and $L_{\max }$ defines minimum and maximum length values of the cantilevers. $L_{\min }$ was set to $75 \mathrm{~mm}$ while $L_{\max }$ was set to $85 \mathrm{~mm}$.

Results of calculations are presented in Figure $3 \mathrm{a}, \mathrm{b}$ where von Mises stress are shown at resonant frequencies when different values of $L_{1}$ and $L_{2}$ and base acceleration direction align to $z$ and $y$ axis.

Analyzing results shown in Figure $3 a$ it can be noted that the highest average von Mises stress value of $1.2 \times 10^{8} \mathrm{~N} / \mathrm{m}^{2}$ has been obtained when cantilever lengths are $L_{1}=83 \mathrm{~mm}$ and $77 \mathrm{~mm}<L_{2}<$ $79 \mathrm{~mm}$. It means that $L_{1}$ must be kept at a particular value, while $L_{2}$ can be selected within the defined range. It gives flexibility in the combination of cantilevers lengths while excitation directions and resonant frequencies are different.

Figure $3 \mathrm{~b}$ shows that the highest average von Mises stress value of $1.65 \times 10^{6} \mathrm{~N} / \mathrm{m}^{2}$ is obtained when $L_{1}=83 \mathrm{~mm}$, while $80 \mathrm{~mm}<L_{2}<83 \mathrm{~mm}$. It can be noticed that the maximum average von Mises stress value is notably lower compared to the case with excitation in $z$-axis. Such difference occurred because of the $\alpha_{1}$ and $\alpha_{2}$ angles and different bending forces, respectively. As the length value of cantilever $L_{1}$ is the same in both excitation cases, it was used as optimal. However, the length value of cantilever $L_{2}$ does not match when different excitation direction is applied. As optimal $L_{2}$ value was selected length value of $79 \mathrm{~mm}$, considering that average von Mises stress values are notably higher 
compare when acceleration in $z$ direction applied. Also, this value is the closest possible value to the range of $L_{2}$ values when acceleration direction coincides with $y$ direction.

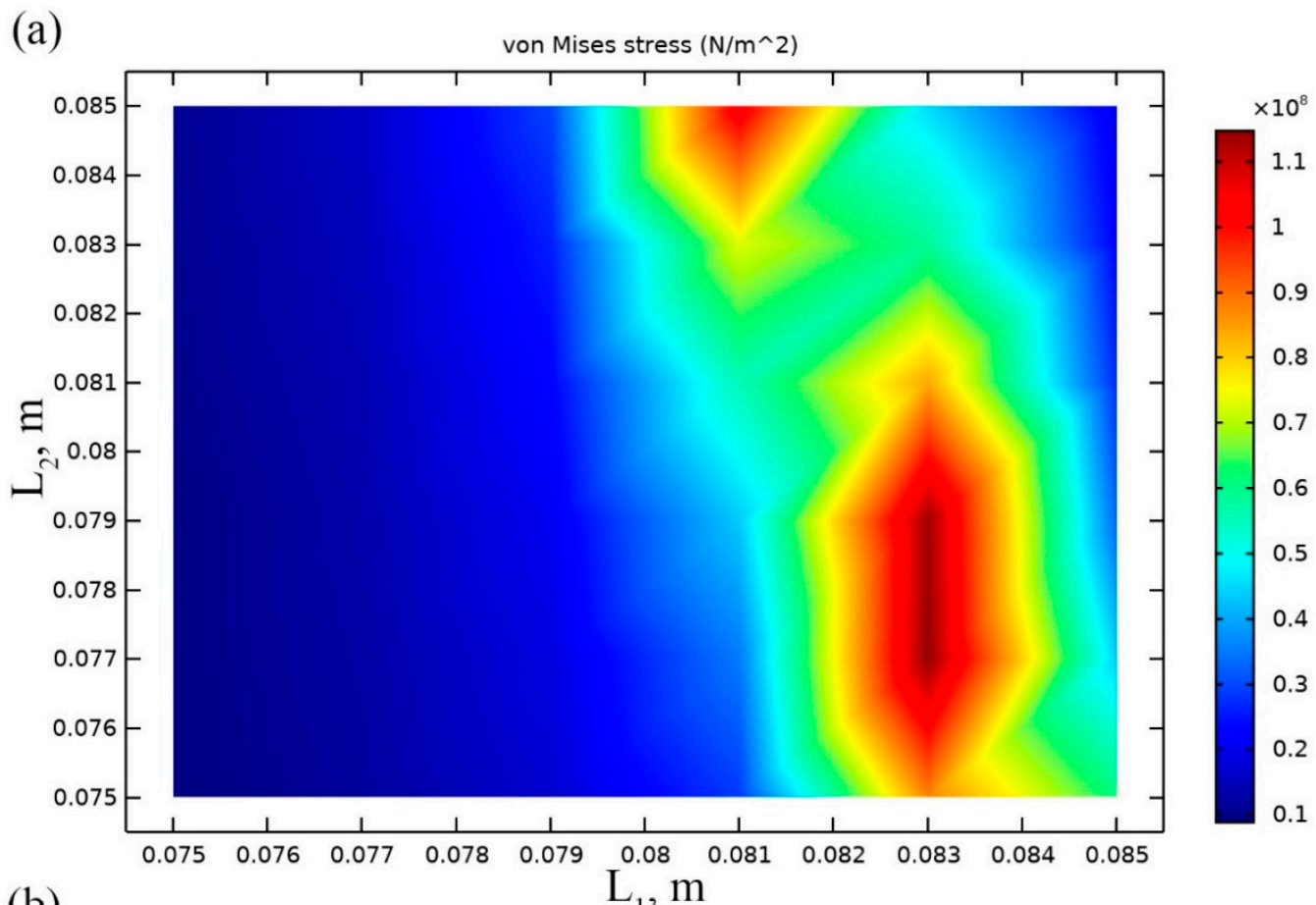

(b)

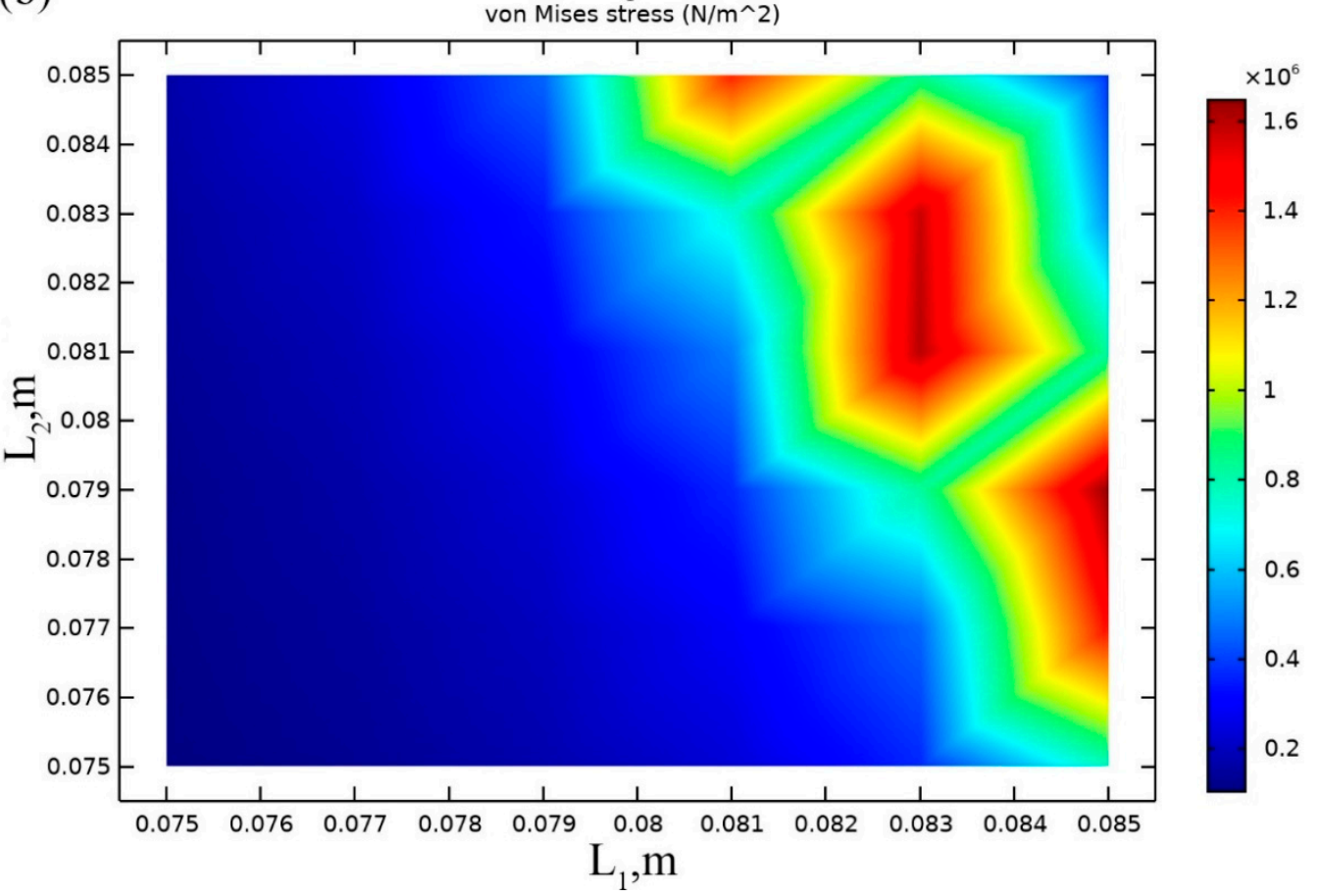

Figure 3. Plot of von Mises stresses at the resonance frequency when different $L_{1}$ and $L_{2}$ values are used: acceleration aligned to $z$ direction, resonant frequency $24 \mathrm{~Hz}(\mathbf{a})$; acceleration aligned to $y$ direction, resonant frequency $33 \mathrm{~Hz}(\mathbf{b})$.

Next optimization step was arranged to find optimal masses of seismic masses placed at tip and at the junction between cantilevers. Length of the cantilevers were set to optimal values obtained during previous investigation i.e., $L_{1}=83 \mathrm{~mm} ; L_{2}=79 \mathrm{~mm}$ while angles $\left(\alpha_{1}\right.$ and $\left.\alpha_{2}\right)$ were set to initial values 
which are in Table 2. Average von Misses stress along the both cantilevers was chosen as objective of the optimization problem as in the previous step. The optimization problem can be written as follows:

$$
\max _{m}\left(\sigma_{\operatorname{avg}}(M)\right)
$$

subjected to

$$
\begin{gathered}
M_{\min } \leq L_{i} \leq M_{\max } \\
\sigma_{a v g}<\sigma_{t}
\end{gathered}
$$

where

$$
m=\left(M_{1}, M_{2}\right)
$$

here $\sigma_{\text {avg }}$ average von Misses stress inducted along cantilevers; $\sigma_{t}$ tensile strength of 6061 aluminum alloy; $M_{1}$ and $M_{2}$ are masses of the seismic masses; $M_{\min }$ and $M_{\max }$ defines minimum and maximum values of seismic masses mass. Lower bound of the interval $M_{\min }$ was set to $3 \mathrm{~g}$ and $M_{\max }$ was set to $6 \mathrm{~g}$.

Results of calculations are presented in Figure $4 \mathrm{a}, \mathrm{b}$ where von Mises stress are shown at resonant frequencies when different masses values and base acceleration direction align to $z$ and $y$ axis.

Analysis of Figure 4a showed that the highest average von Mises stress value of $5.5 \times 10^{8} \mathrm{~N} / \mathrm{m}^{2}$ was obtained at the resonant frequency of $15 \mathrm{~Hz}$. This value has been obtained when $M_{1}=3.04 \mathrm{~g}$ and $3.3 \mathrm{~g}<M_{2}<4.25 \mathrm{~g}$. It can be noted that von Mises stress value is more than 5 times higher compared to the result obtained in the previous step of optimization. Moreover, resonant frequencies of the harvester slightly decreased.

During analysis of the results presented in $4 \mathrm{~b}$, it can be noted that maximum average von Mises stress value is $1.1 \times 10^{6} \mathrm{~N} / \mathrm{m}^{2}$ while excitation frequency was set to $28 \mathrm{~Hz}$. This stress value is slightly lower compared to the result obtained in the $L_{1}, L_{2}$ optimization step. Two optimal pair of seismic mass $M_{1}$ and $M_{2}$ values was obtain i.e., $M_{1}=3.04 \mathrm{~g}, M_{2}=4.25 \mathrm{~g}$ and $M_{1}=4.25 \mathrm{~g}, M_{2}=3.04 \mathrm{~g}$. It can be concluded that values of optimal seismic masses for excitation in $z$ and $y$ directions are in coincidence and can be used for both directions. We decided to select the first pair of mass values $M_{1}=3.04 \mathrm{~g}$, $M_{2}=4.25 \mathrm{~g}$ for further investigation.

The last step of optimization was performed to find optimal angles $\alpha_{1}$ and $\alpha_{2}$. Length of the cantilevers and mass of seismic masses were set to optimal values obtained during previous investigations i.e., $L_{1}=83 \mathrm{~mm} ; L_{2}=79 \mathrm{~mm}$ and $M_{1}=3.04 \mathrm{~g}, M_{2}=4.25 \mathrm{~g}$, respectively. Average von Misses stress along the both cantilevers was chosen as objective of the optimization problem as in the previous steps. Optimization problem can be written as follows:

$$
\max _{m}\left(\sigma_{\text {avg }}()\right)
$$

subjected to

$$
\begin{gathered}
\alpha_{\min } \leq \alpha_{i} \leq \alpha_{\max } \\
\sigma_{a v g}<\sigma_{t}
\end{gathered}
$$

where

$$
A=\left(\alpha_{1}, \alpha_{2}\right)
$$

here $\sigma_{a v g}$ average von Mises stress inducted along cantilevers; $\sigma_{t}$ tensile strength of 6061 aluminum alloy; $\alpha_{1}$ and $\alpha_{2}$ are angles; $\alpha_{\min }$ and $\alpha_{\max }$ defines minimum and maximum values for the angles. Minimum value $\alpha_{\min }$ was set to $1.13 \mathrm{rad}$ and maximum value $\alpha_{\max }$ was set to $2.7 \mathrm{rad}$.

Results of calculations are presented in Figure $5 \mathrm{a}, \mathrm{b}$ where von Mises stresses are shown at resonant frequencies when different angle values and base acceleration direction align to $z$ and $y$ axis. 

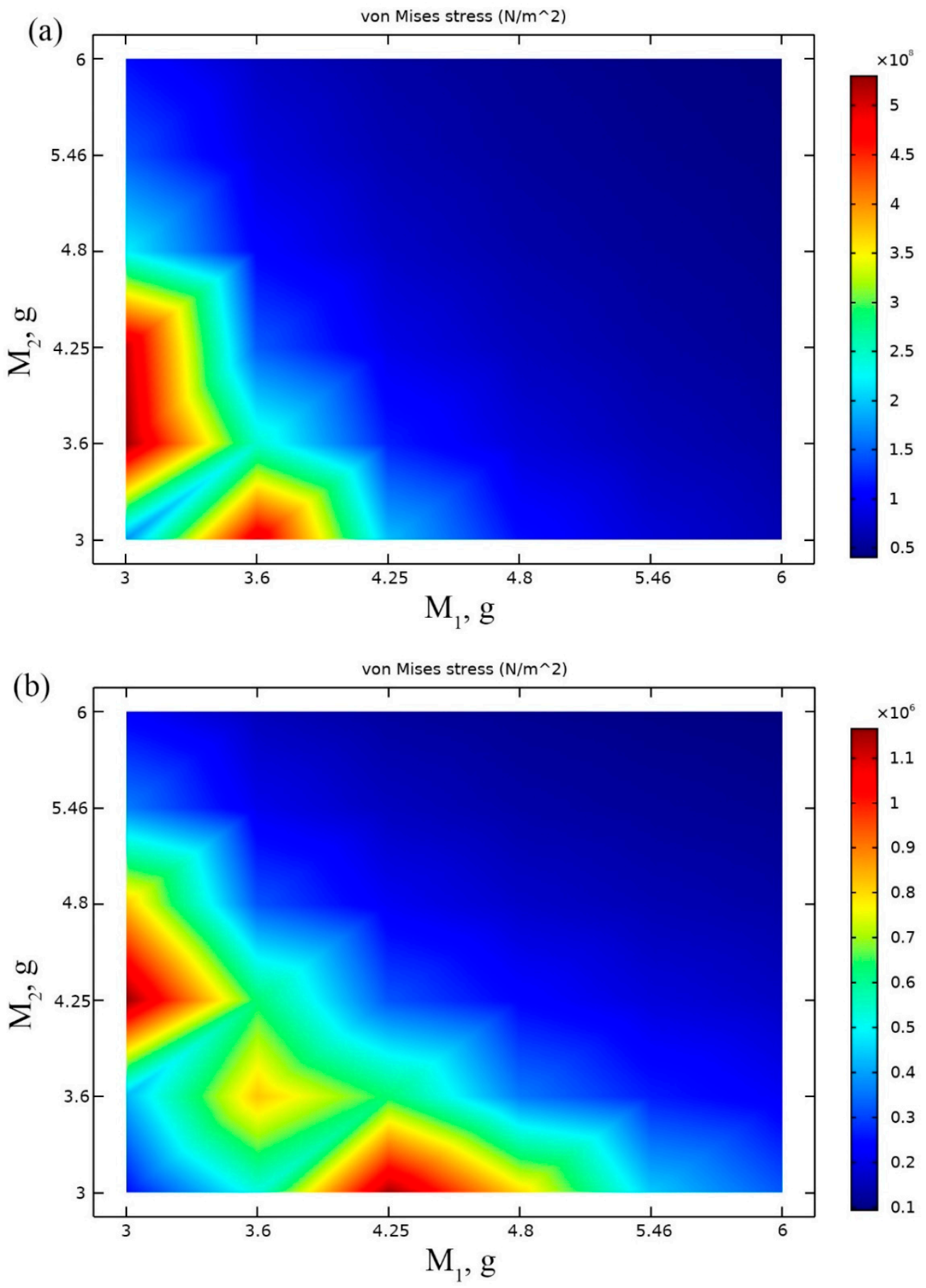

Figure 4. Plot of von Mises stresses at the resonance frequency when different $M_{1}$ and $M_{2}$ are used: acceleration aligned to $z$ direction, resonant frequency $15 \mathrm{~Hz}(\mathbf{a})$; acceleration aligned to $y$ direction, resonant frequency $28 \mathrm{~Hz}(\mathbf{b})$.

Analysis of Figure 5a showed that optimal values of angles $\alpha_{1}$ and $\alpha_{2}$ are $2.75 \mathrm{rad}$ and $1.38 \mathrm{rad}$, respectively. Average von Mises stress of $5.8 \times 10^{8} \mathrm{~N} / \mathrm{m}^{2}$ is obtained in this case. Optimal angles allowed improve of average von Mises stress value by $0.3 \times 10^{8} \mathrm{~N} / \mathrm{m}^{2}$ or $5.17 \%$.

When the direction of the base acceleration was aligned to the direction of $y$ axis, the largest average von Mises stress of $6.8 \times 10^{6} \mathrm{~N} / \mathrm{m}^{2}$ was obtained when $\alpha_{1}=2.45 \mathrm{rad}$ and $\alpha_{2}=1.38 \mathrm{rad}$. The average stress value has increased about 5 times compared to the previous results. It shows that these angles ensure notable stress increment. However, obtained $\alpha_{1}$ values do not match when 
acceleration is applied in $z$ and $y$ directions. We decided to select $\alpha_{1}$ value of 2.75 rad because higher average von Mises stress value was obtained when acceleration direction coincide with $z$ axis.

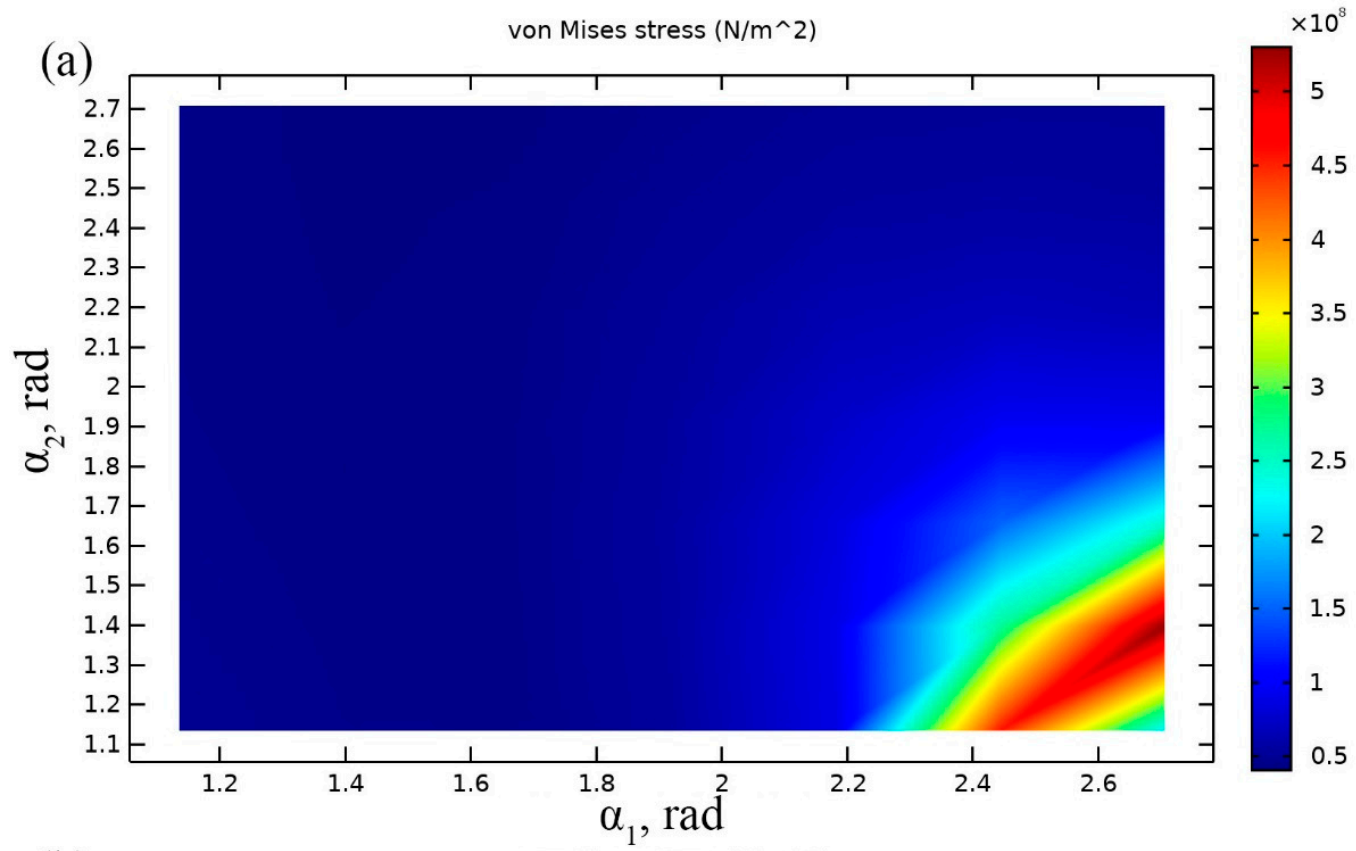

(b)

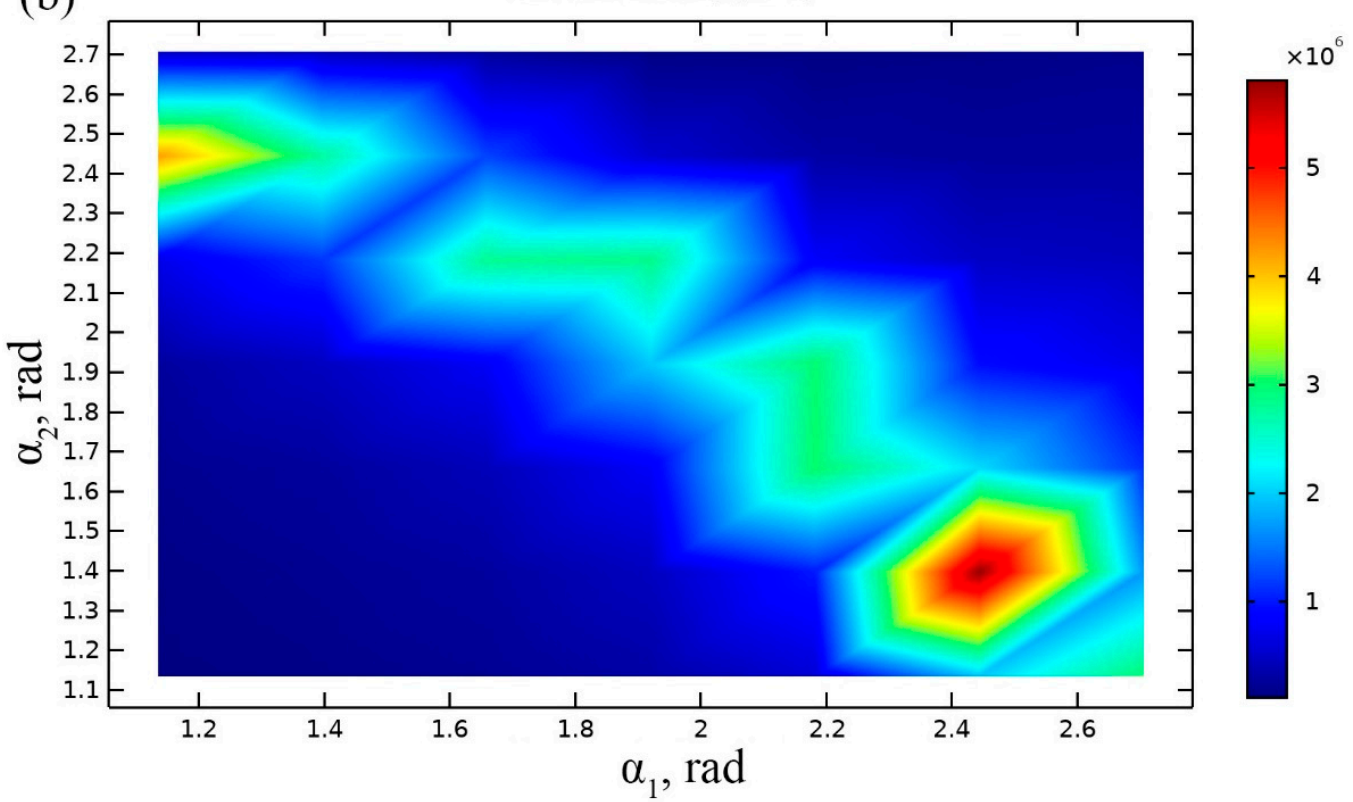

Figure 5. Plot of von Mises stresses at the resonance frequency when different $\alpha_{1}$ and $\alpha_{2}$ are used: acceleration aligned to $z$ direction, resonant frequency $14 \mathrm{~Hz}(\mathbf{a})$; acceleration aligned to $y$ direction, resonant frequency $27 \mathrm{~Hz}(\mathbf{b})$.

The optimal geometrical parameters of the bidirectional energy harvester was obtained and are listed in Table 3. 
Table 3. Geometrical and physical parameters of the harvester.

\begin{tabular}{ccc}
\hline Parameter & Value & Description \\
\hline $\mathrm{L}_{1}$ & $83 \mathrm{~mm}$ & Length of first cantilever \\
\hline $\mathrm{L}_{2}$ & $79 \mathrm{~mm}$ & Length of second cantilever \\
\hline $\mathrm{t}$ & $0.6 \mathrm{~mm}$ & Thickness of the cantilevers \\
\hline $\mathrm{PZT}_{1}$ & $0.9 \mathrm{~L}_{1}, \mathrm{~mm}$ & Length of piezo ceramics placed on $\mathrm{L}_{1}$ \\
\hline $\mathrm{PZT}_{2}$ & $0.9 \mathrm{~L}_{2}, \mathrm{~mm}$ & Length of piezo ceramics placed on $\mathrm{L}_{2}$ \\
\hline $\mathrm{t}_{\mathrm{pzt}}$ & $0.2 \mathrm{~mm}$ & Thickness of piezo ceramic layer \\
\hline $\mathrm{t}_{\text {total }}$ & $1 \mathrm{~mm}$ & Thickness of bimorphs \\
\hline$\alpha_{1}$ & $2.75 \mathrm{rad}$ & Angle between clamping base and $\mathrm{L}_{1}$ \\
\hline$\alpha_{2}$ & $1.38 \mathrm{rad}$ & Angle between $\mathrm{L}_{1}$ and $\mathrm{L}_{2}$ \\
\hline $\mathrm{M}_{1}$ & $3.04 \mathrm{~g}$ & Seismic mass placed at junction between $\mathrm{L}_{1}$ and $\mathrm{L}_{2}$ \\
\hline $\mathrm{M}_{2}$ & $4.25 \mathrm{~g}$ & Seismic mass placed at tip of $\mathrm{L}_{1}$ \\
\hline $\mathrm{w}$ & $5 \mathrm{~mm}$ & Width of whole energy harvester \\
\hline
\end{tabular}

Therefore, in order to verify operation principle and clarify vibration modes, modal analysis of the optimized energy harvester was performed. Results of the modal analysis are given in Figure 6. It can be seen that energy harvester operates at the first and second vibration mode. During excitation in $y$ direction vibration mode at $13.825 \mathrm{~Hz}$ will be dominant and will generate the most power output. On the other hand, during excitation in $z$ direction vibration mode at $25.87 \mathrm{~Hz}$ becomes dominant and also will generate the power output. Domination of the vibration modes depends on excitation direction and it is related with the shifted mass center and additional rotation moment created by these masses. The shift of the mass center occurs because of the angles between cantilevers, while rotation is obtained by different values of seismic masses. Moreover, rotation moment magnifies bending and increase stress inducted in the cantilevers. Therefore, the first vibration mode is dominant during excitation in $y$ direction due to the bending and rotation of the harvester. The second vibration mode is dominant only due to bending while rotation moment much lower when excitation in $z$ direction is applied.

(a)

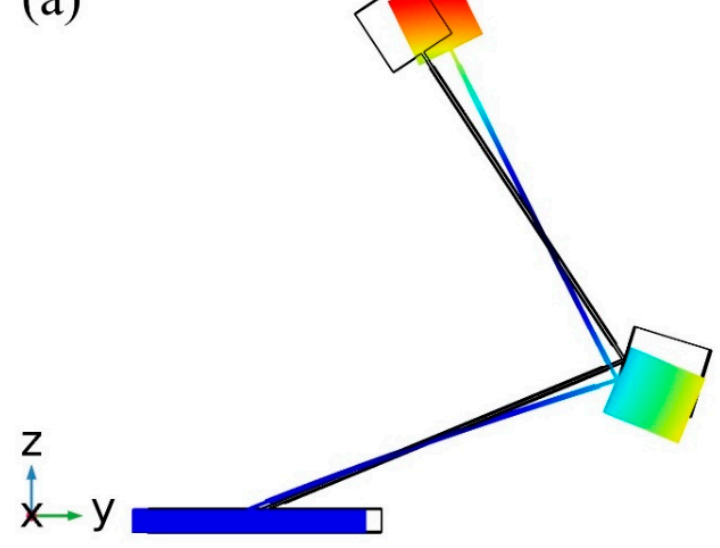

(b)

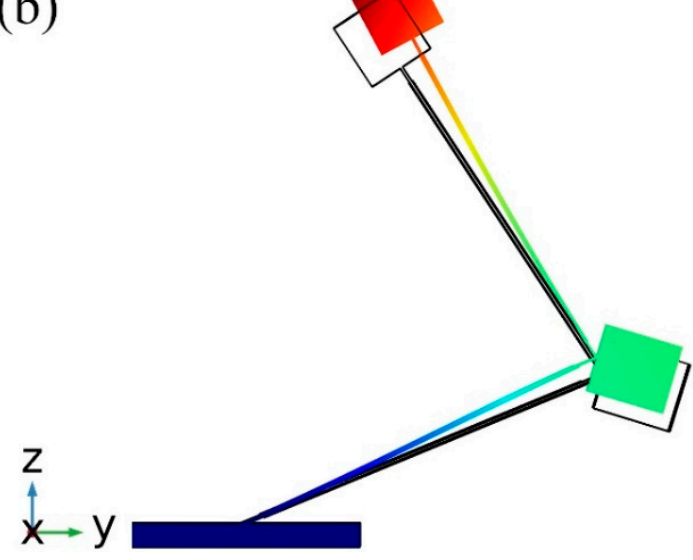

Figure 6. Vibration modes of bidirectional energy harvester; (a)-vibration shape at $13.825 \mathrm{~Hz}$; (b)-vibration shape at $25.87 \mathrm{~Hz}$.

In order to analyze reliability of the proposed energy harvester, dependence of the von Mises stress of the harvester from acceleration amplitudes in $y$ and $z$ directions was investigated (Figures 7 and 8). Acceleration range was set from $0.1 \mathrm{~m} / \mathrm{s}^{2}$ to $25 \mathrm{~m} / \mathrm{s}^{2}$. Step size was $0.1 \mathrm{~m} / \mathrm{s}^{2}$. The investigation was performed at two resonant frequencies i.e., $13.8 \mathrm{~Hz}$ and $25.87 \mathrm{~Hz}$. It was considered that PZT-5 
piezoceramic tensile stress is $50 \cdot \mathrm{MPa}$, and it was examined that obtained stress does not exceed tensile stress when acceleration is increasing.

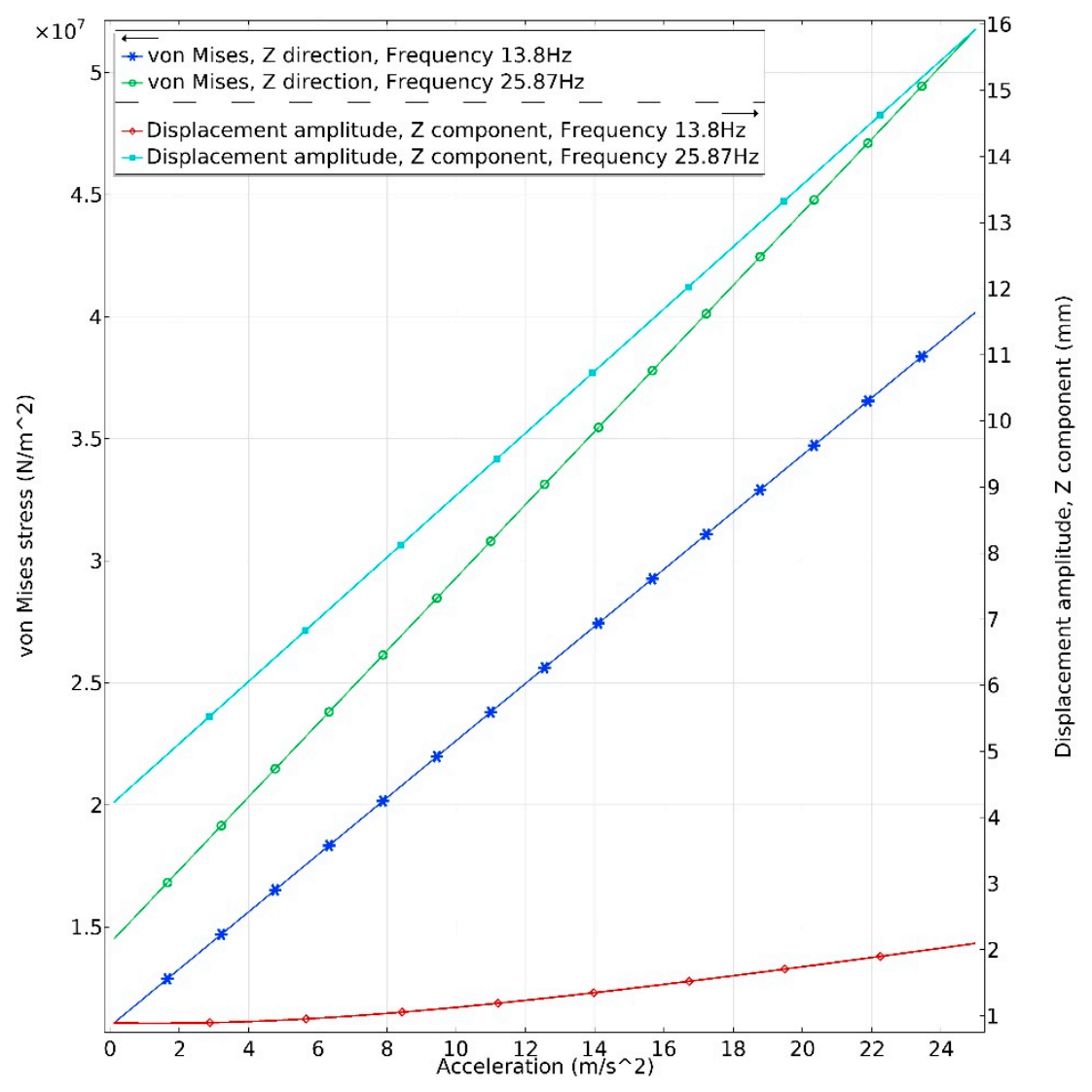

Figure 7. Dependence of maximum von Mises stress and tip displacement from acceleration in $z$ direction.

Analyzing results presented in Figure 7, it can be noted that the upper limit of acceleration in $z$ direction is $23 \mathrm{~m} / \mathrm{s}^{2}$ when host excitation frequency is $13.8 \mathrm{~Hz}$. The maximum stress of $42 \cdot \mathrm{MPa}$ is obtained while the displacement of the tip is $1.8 \mathrm{~mm}$. The upper acceleration limit of the harvester is $22.3 \mathrm{~m} / \mathrm{s}^{2}$ at the host excitation frequency of $25.8 \mathrm{~Hz}$. The maximum stress of $48 \cdot \mathrm{MPa}$ is obtained while tip displacement is $14.8 \mathrm{~mm}$.

Figure 8 shows the maximum von Mises stress inducted in energy harvester during excitation in the $y$ direction at resonance frequencies of $13.8 \mathrm{~Hz}$ and $25.8 \mathrm{~Hz}$. The maximum stress of $12.5 \cdot \mathrm{MPa}$ and tip displacement of $5.8 \mathrm{~mm}$ is obtained at the frequency of $13.8 \mathrm{~Hz}$ when acceleration amplitude was $25 \mathrm{~m} / \mathrm{s}^{2}$. The maximum stress of $0.6 \cdot \mathrm{MPa}$ and tip displacement of $1.1 \mathrm{~mm}$ was obtained at the resonance frequency of $25.8 \mathrm{~Hz}$ when acceleration amplitude was $25 \mathrm{~m} / \mathrm{s}^{2}$.

Based on the obtained results, it can be concluded that energy harvester can operate at high acceleration amplitude. However, it must be noted that numerical simulation was performed, considering that vibrations are linear. Large tip displacement values obtained when excitation in the $z$ direction is applied at a frequency of $25.8 \mathrm{~Hz}$ indicate that fatigue problem can occur. Therefore, the maximum acceleration value must be less than mentioned before. Although the proposed energy harvester is suitable for high acceleration values, we focused on the low-level excitation amplitudes. Therefore, the main results presented in this paper were obtained when acceleration was $0.1 \mathrm{~m} / \mathrm{s}^{2}$. 


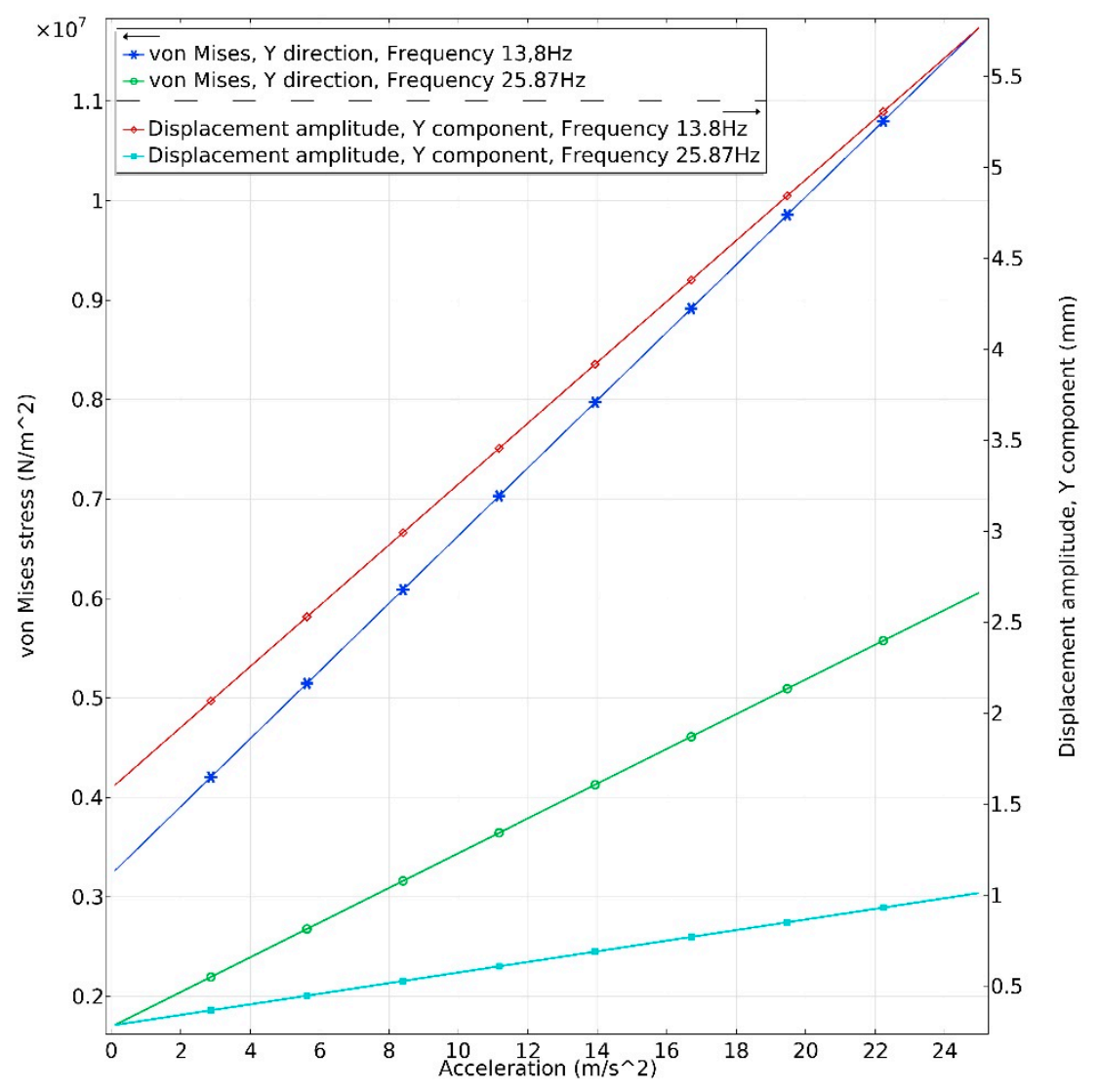

Figure 8. Dependence of maximum von Mises stress and tip displacement from acceleration in $y$ direction.

To prevent the proposed energy harvester from possible failure at high acceleration amplitude, electronic damping can be used. Additional resistive, capacitive or inductive shunt circuit can be connected in parallel to one of piezoceramic plate in order to damp vibrations of the harvester and dissipate electrical energy as heat. Also, active damping systems can be used for the same purpose, i.e., an out-of-phase actuation can be generated applying external DC or out-of-phase AC voltage to one of the piezo ceramic plates to prevent the harvester from failure.

Amplitude-frequency characteristic of the energy harvester was calculated when acceleration in $y$ and $z$ direction was applied. Frequency range from $5 \mathrm{~Hz}$ to $40 \mathrm{~Hz}$ was analyzed when acceleration was set to $0.1 \mathrm{~m} / \mathrm{s}^{2}$. Results are shown in Figure 9 .

Displacement amplitude-frequency characteristics was calculated for point located at free end of the energy harvester. Calculated resonant frequencies are in good agreement with the results obtained during modal analysis. It can be found that during excitation in $y$ direction the highest displacement amplitude, $17.7 \mathrm{~mm}$, was obtained at the first resonance. It shows that energy harvester will be able deliver the highest electrical characteristics during excitation by force with $13.825 \mathrm{~Hz}$ frequency and vector aligned to the $y$ axis. On the other hand, the second resonance also will be employed. However, according to the displacement amplitude value equal to $4.1 \mathrm{~mm}$, the electrical characteristics will be much lower compare to the first resonance. Therefore, it can be concluded that during excitation in $y$ direction the best characteristics will be obtained during harvesters operation at the first resonance.

During harvester's excitation in $z$ direction, the highest displacement amplitude was obtained at $25.87 \mathrm{~Hz}$ frequency i.e., the second resonance. Displacement amplitude at this frequency reached $9.3 \mathrm{~mm}$. As in the case before can be assumed that the highest electrical characteristics will be obtained at this frequency. Also, displacement amplitude-frequency characteristic shows that the first resonance is also employed. However, displacement amplitude is much lower i.e., $4.9 \mathrm{~mm}$. 


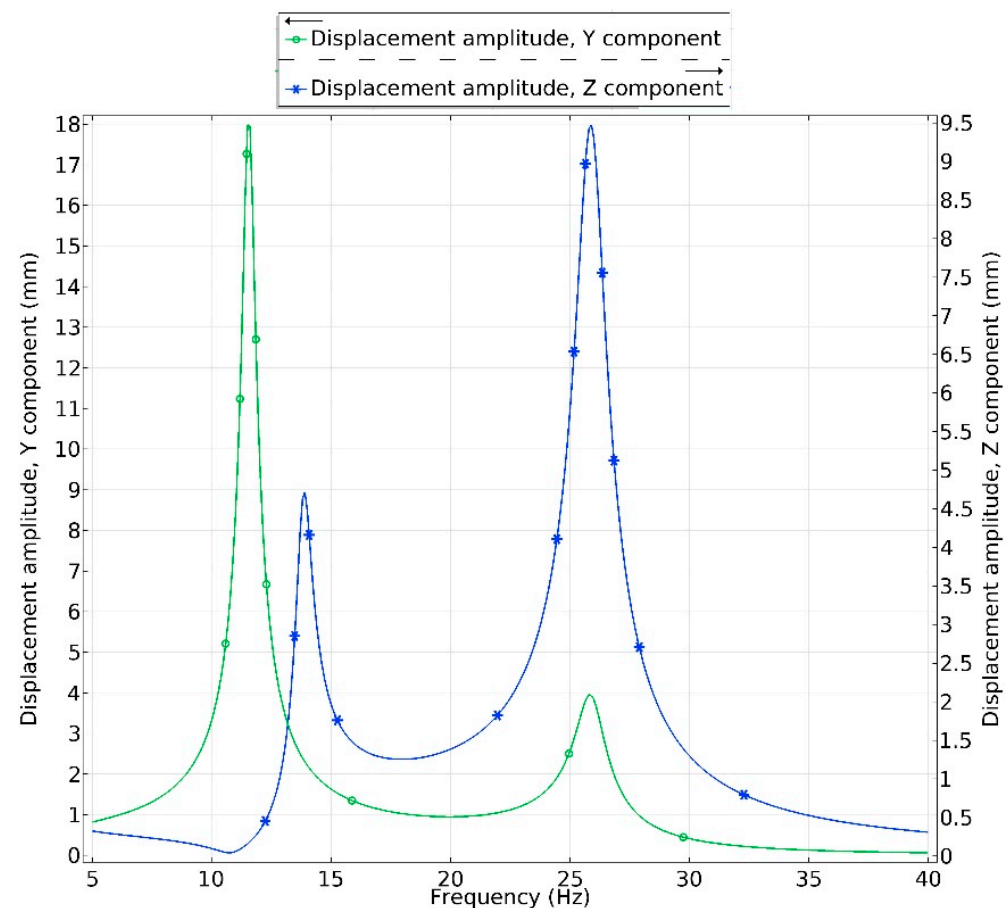

Figure 9. Displacement amplitude—frequency characteristics of bidirectional energy harvester.

The results show that bidirectional energy harvester will be able to deliver energy during excitation in $y$ and $z$ directions by employing both resonances. However, it can be assumed that electrical characteristics will be unstable considering to excitation direction, vibration mode, excitation frequency and different stiffness of structure in $y$ and $z$ directions.

In order to accurately assess mechanical characteristics of the harvester, bending strains inducted in piezo ceramic were investigated. An investigation was performed on each cantilever separately during base excitation in $y$ and $z$ directions. Results are given in Figures 10 and 11.

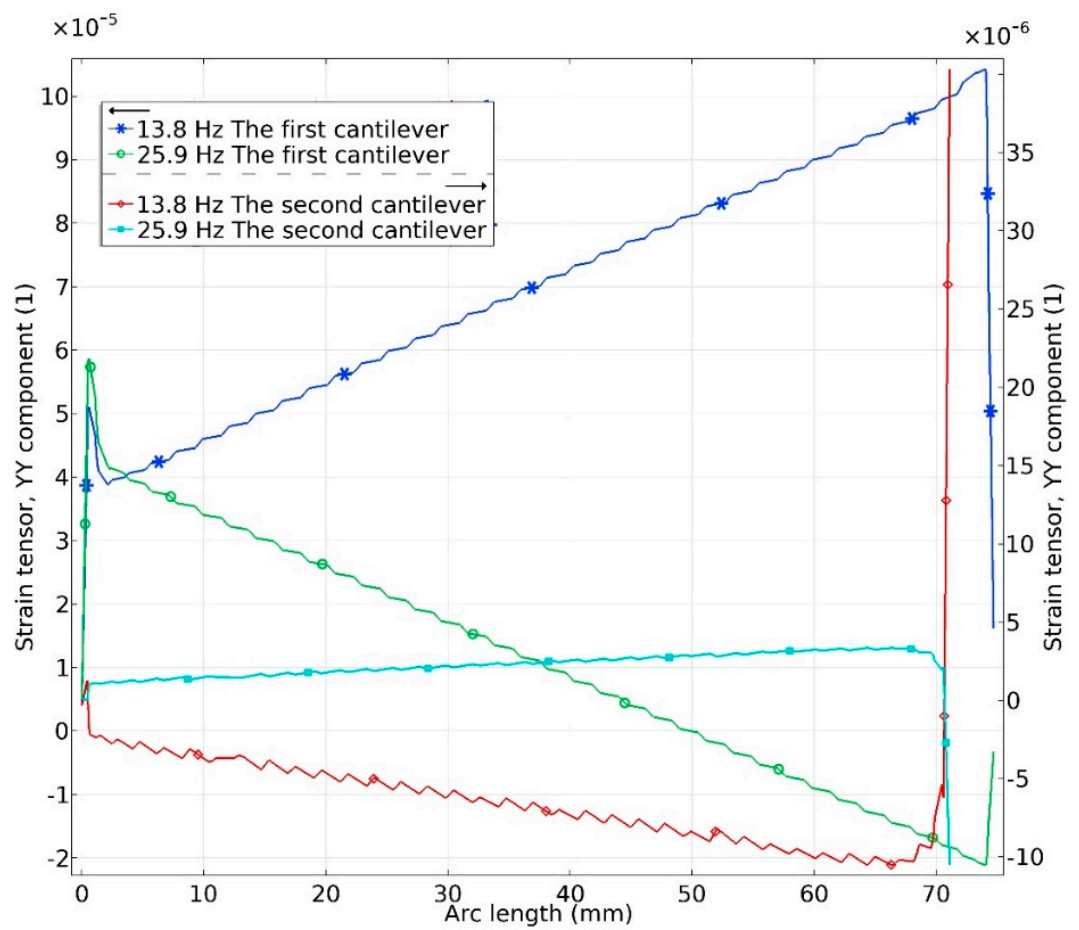

Figure 10. Bending strain characteristics at resonant frequencies during base excitation in $y$ direction. 


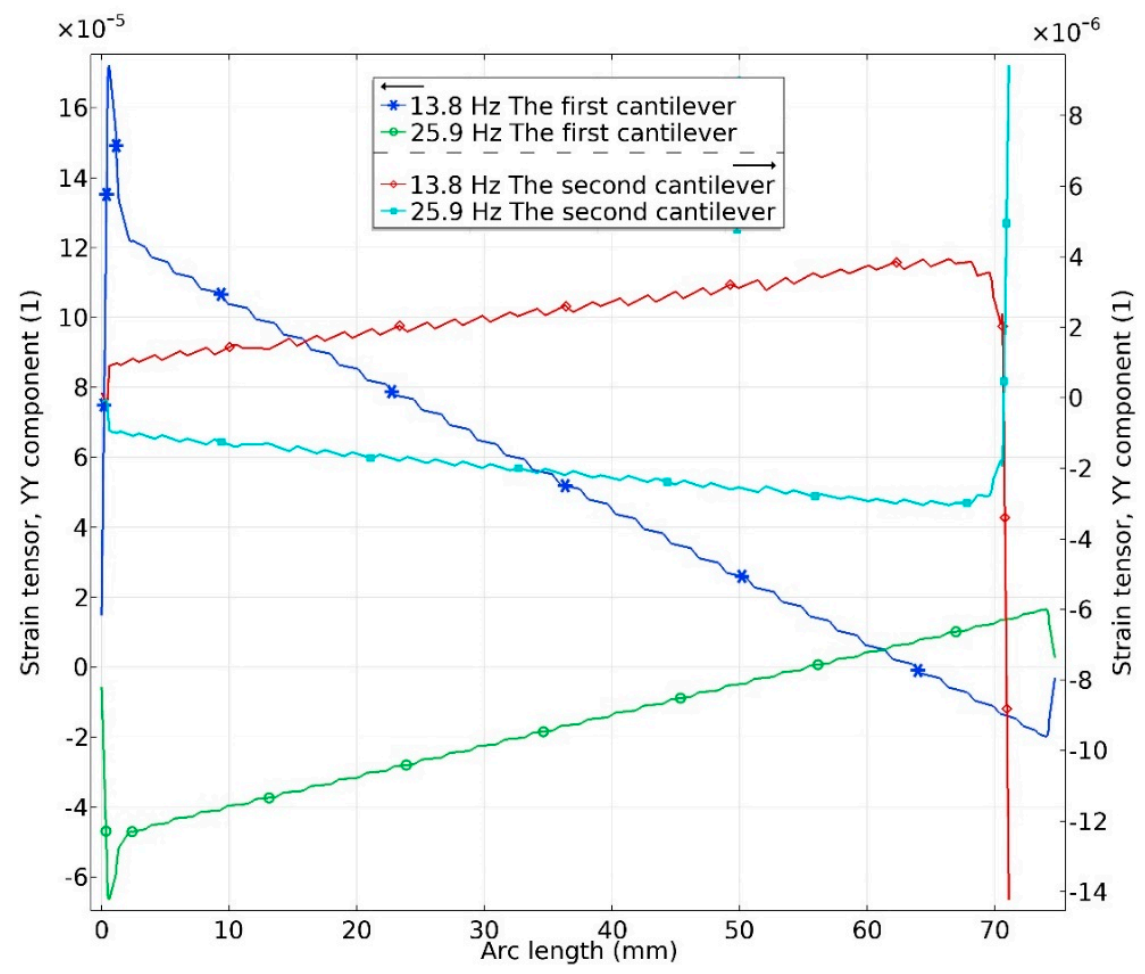

Figure 11. Bending strain characteristics at resonant frequencies during excitation in $z$ direction.

Analysis of graphs presented in Figure 10 showed that considering to the resonant frequency, differences in bending strain values between the first and second cantilevers are around 10 times. The bending strain characteristics shows that the most bending strain is concentrated at the first cantilever. It can be assumed that the first cantilever will generate the most of electrical power while the second cantilever will generate much lower output ant will be more passive. However, it acts as an additional mass attached to the first cantilever thru lever arm and ensures additional rotation moment an as a result the higher electrical characteristics of whole energy harvester.

As can be found in Figure 11 the highest bending strain values are obtained at first cantilever. As in the case with excitation in $y$ direction, differences in bending strain values between the first and second cantilevers are more than 10 times. According to Figure 11 it can be concluded that the highest bending strain values are at the first cantilever while the strain inducted in the second cantilever is notably lower. As in the case with excitation in the $y$ direction, most of the electrical energy will be generated by the first cantilever while the second cantilever will provide much lower electrical characteristics. In summary of this part of investigations, can be concluded that the most of power will be generated by the first cantilever during excitation in $y$ and $z$ directions, while the second cantilever acts as an active system which ensures capture of excitation forces with different directions as well as delivers additional power output.

The output voltage of the energy harvester was investigated at the frequency range from $5 \mathrm{~Hz}$ to $35 \mathrm{~Hz}$. Acceleration was set to $0.1 \mathrm{~m} / \mathrm{s}^{2}$. Results of the calculations are given in Figure 12. It can be seen that output voltage during excitation in $y$ direction has the highest value at the first resonant frequency. It value reached $7.3 \mathrm{~V}_{\mathrm{p}-\mathrm{p}}$, while voltage of $2.8 \mathrm{~V}_{\mathrm{p}-\mathrm{p}}$. is obtained at the second resonant frequency. During excitation in $z$ direction, the highest output voltage was obtained at the second resonant frequency. It value reached $7.1 \mathrm{~V}_{\mathrm{p}-\mathrm{p}}$, while output voltage at the first resonant frequency was $3.1 \mathrm{~V}_{\mathrm{p}-\mathrm{p}}$. Obtained results of output voltage confirm results given in Figures 10 and 11 and correspond to bending strain distribution. Moreover, obtained results shows that energy harvester is able to provide a stable output voltage at different resonant frequencies. Also, it shows that energy harvester is able to operate with excitation forces aligned to the different axis and provide stable electrical outputs. 


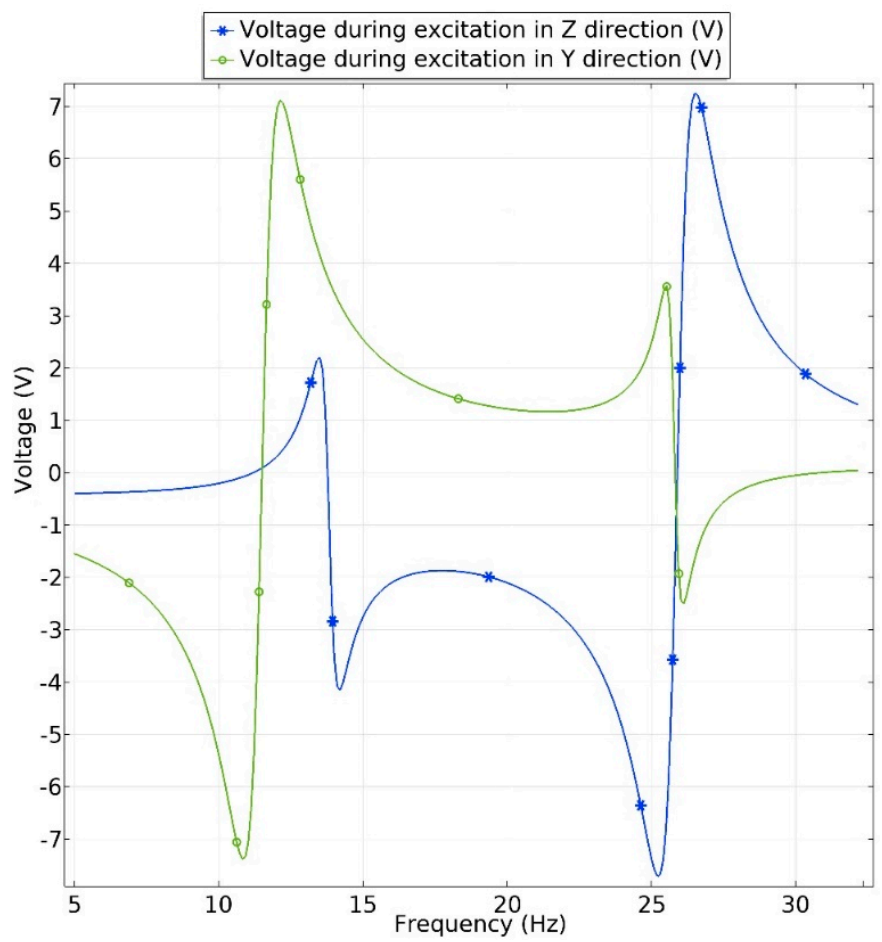

Figure 12. Total output voltage of bidirectional energy harvester.

\section{Experimental Investigation}

An experimental investigation was performed to measure the electrical and mechanical characteristics of bidirectional energy harvester. A prototype of the harvester was made (Figure 13). Geometrical parameters and material properties of the prototype correspond to the characteristics given in Tables 2 and 3.

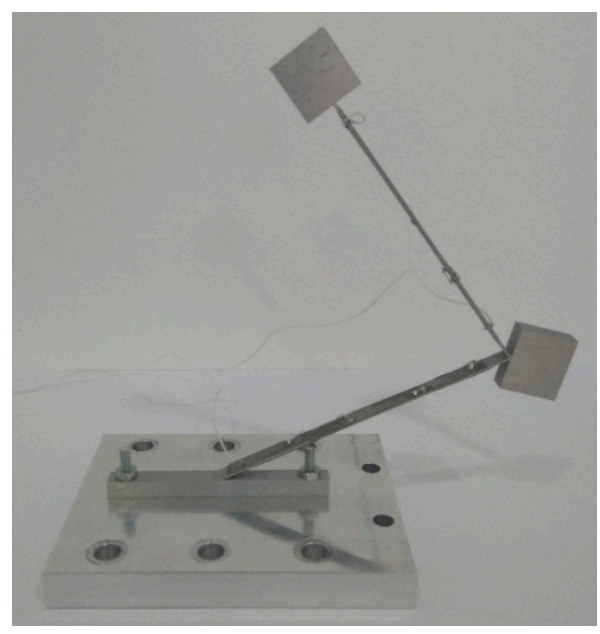

Figure 13. Prototype of bidirectional piezoelectric energy harvester.

The experimental investigation was divided into the three steps i.e., resonant frequencies measurement, measurement of electrical output characteristics when harvester is excited by harmonic force at resonant frequencies and measurement of electrical output characteristics while energy harvester is excited by impact force. Experimental setup was built to perform all experimental investigations. It included two inductive displacement sensors (Models U3B and U20B, Lion precision, Oakdale, CA, USA), power amplifier (Type 2307, Brüel \& Kjær, Nærum, Denmark), function generator (Model WW5064, Tabor Electronics, Tel Hanan, Israel), electromagnetic shaker (Model 4806, HP, 
Palo Alto, CA, USA), programmable custom made resistance load, micro current probe ( $\mu$ Current ${ }^{\mathrm{TM}}$, EEV blog, Sydney, Australia), multichannel oscilloscope (Model DLM2021, Yokogawa, Musashino, Tokyo, Japan), computer with data management software. Schematic of the experimental setup is given in Figure 14. Inductive sensors were used to control displacement of harvester's base and tip. Function generator and amplifier were used to generate harmonic signal to control the displacement of the shaker. Programmable resistance load was used to apply different loads for the harvester. Moreover, multi channel oscilloscope was used to measure and to record current and voltage generated by the energy harvester.

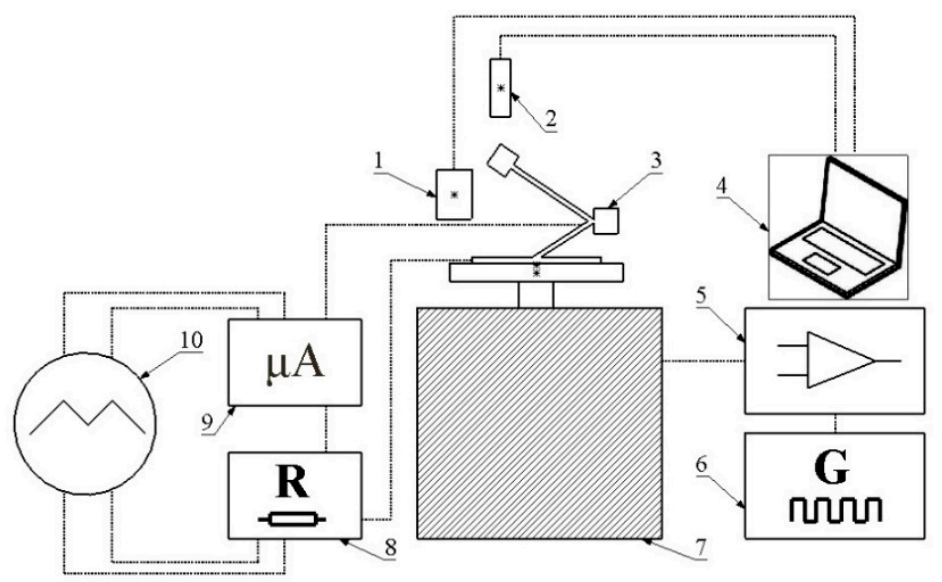

Figure 14. Experimental setup; 1,2-inductive displacement sensors; 3-prototype of the energy harvester; 4-computer with data management software; 5-power amplifier; 6-function generator; 7-electromagnetic shaker; 8-programmable resistance load; 9-micro current probe; 10-multichannel oscilloscope.

Firstly, the frequency response characteristics were measured when excitation directions of the harvester were aligned to $y$ and $z$ directions. Inductive displacement sensors and computer with data acquisition software were employed for the measurement. Frequency range was set the same as used for numerical investigation i.e., from $8 \mathrm{~Hz}$ to $40 \mathrm{~Hz}$. Acceleration amplitude of the shaker was set to $0.001 \mathrm{~m} / \mathrm{s}^{2}$. Acceleration amplitude was reduced compare to the amplitude used during numerical simulation because of limitation of inductive displacement sensor. According to technical specification, sensor can measure displacement up to $0.5 \mathrm{~mm}$ while results of numerical investigation showed that tip displacement is much larger. Results of the measurement are shown in Figure 15.

(a) $\stackrel{[\mathrm{m}] \mathrm{20}}{20 \mathrm{~s}}$

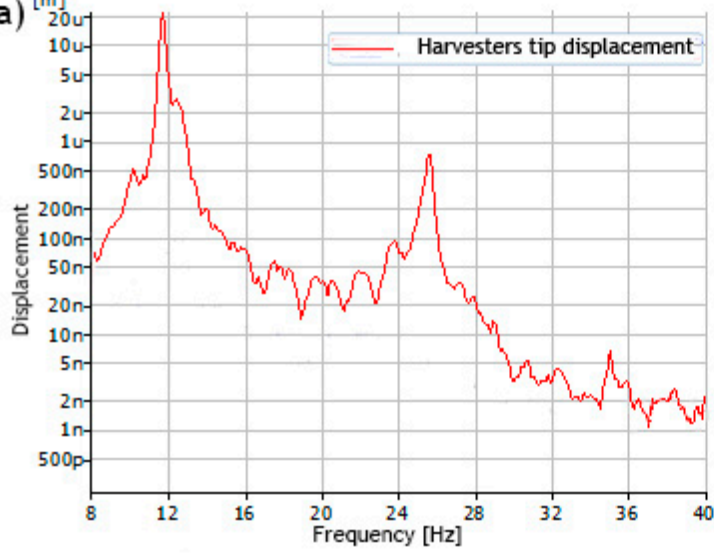

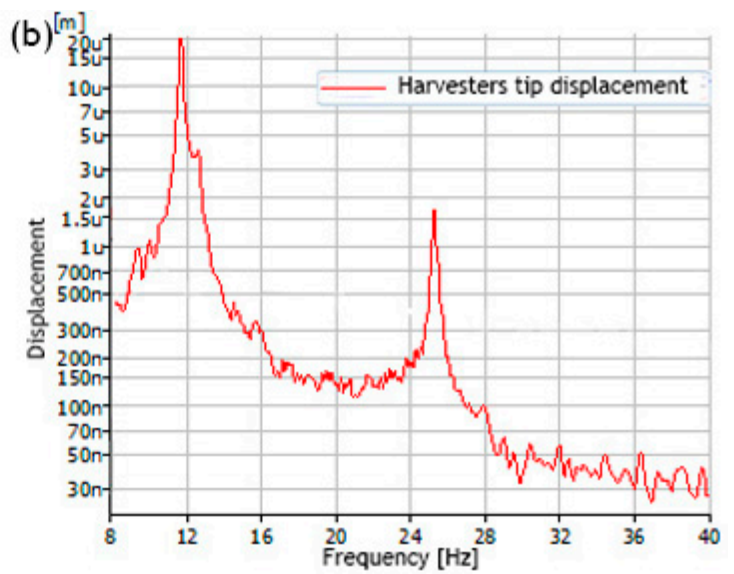

Figure 15. Frequency response characteristics of the bidirectional harvester when excitation direction align with $y$ axis (a) and $z$ axis (b). 
It can be seen that during excitation in $y$ and $z$ directions, resonance frequencies occur at $11.25 \mathrm{~Hz}$ and $26.65 \mathrm{~Hz}$. Resonance frequencies for both excitation cases are the same. Therefore, it can be concluded that bidirectional energy harvester has predictable characteristics during excitation in different directions. Moreover, comparison between results of numerical and experimental investigations showed that differences between resonance frequencies does not exceed $2.55 \mathrm{~Hz}$ for the first resonance and $0.75 \mathrm{~Hz}$ for the second resonance. Vibration amplitudes obtained during numerical and experimental investigations do not match because of different acceleration of the base. On the other hand, further investigations will be made with acceleration amplitude used in numerical investigations i.e., $0.1 \mathrm{~m} / \mathrm{s}^{2}$

During the next experiment, open circuit voltage was measured in the frequency domain. Voltage was measured for each cantilever individually when excitation direction was aligned to $y$ and $z$ axis. Such way of the measurement was done to prevent charge cancelation because of the phase difference of output voltage. Results of measurements are shown in Figure 16.
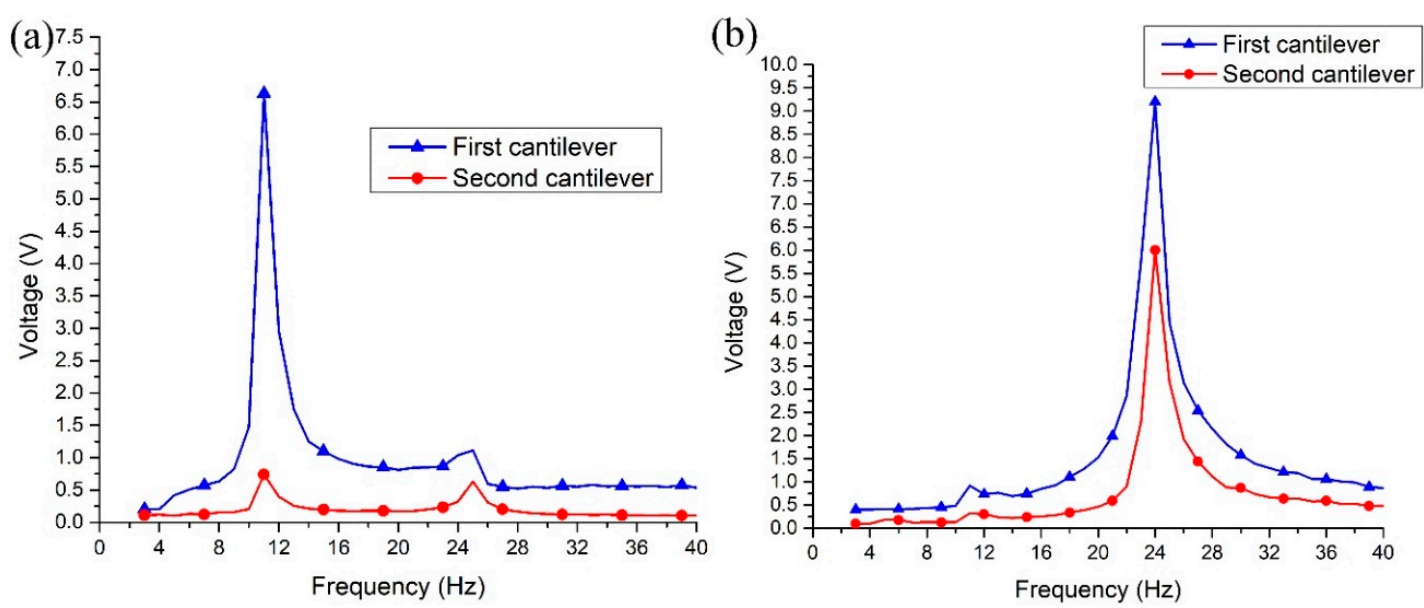

Figure 16. Measured open circuit voltage versus frequency when excitation direction is aligned with $y$ axis (a) and $z$ axis (b).

Analyzing results shown in Figure 16a, it can be noted that the largest output voltage is generated at the first resonant frequency when excitation direction is aligned to $y$ direction. The first cantilever generates the maximum voltage of $6.7 \mathrm{~V}$, while the second cantilever generates $0.73 \mathrm{~V}$. Therefore, energy harvester provides a total voltage of $7.43 \mathrm{~V}$ in parallel circuit case at the first resonance. The first cantilever generates the maximum voltage of $1.11 \mathrm{~V}$ and the second cantilever generates $0.63 \mathrm{~V}$ at the second resonant frequency. The total voltage of $1.73 \mathrm{~V}$ is obtained in parallel circuit case at the second resonant frequency.

Analysis of measurement results when excitation direction is aligned to $z$ axis (Figure 16b) shows, that the maximum voltage of $9.2 \mathrm{~V}$ is obtained at the first cantilever and $6.1 \mathrm{~V}$ at the second cantilever when harvester vibrates at the second resonant frequency. Total voltage of $15.3 \mathrm{~V}$ is obtained in parallel circuit case. This value is $55.9 \%$ higher compare to the total voltage obtained when excitation direction was aligned to $y$ axis. Moreover, the maximum output voltage generated by the first cantilever is $0.77 \mathrm{~V}$ while the second cantilever generates up to $0.24 \mathrm{~V}$. In total the energy harvester generates $1.01 \mathrm{~V}$ at the first resonant frequency during excitation in $z$ direction.

Based on the results of the open circuit voltage measurement, it can be concluded that energy harvester can harvest kinetic energy when bidirectional excitation is applied. The first resonant frequency should be used as operating frequency when excitation direction is aligned to $y$ axis and the second resonant frequency when excitation direction is aligned to $z$ axis.

Electrical output power at the resonant frequencies was measured as well. Measurements were performed when different resistance loads were applied. The resistance range was from $100 \mathrm{k} \Omega$ to $1 \mathrm{M} \Omega$. Results of measurements are presented in Figure 17. 

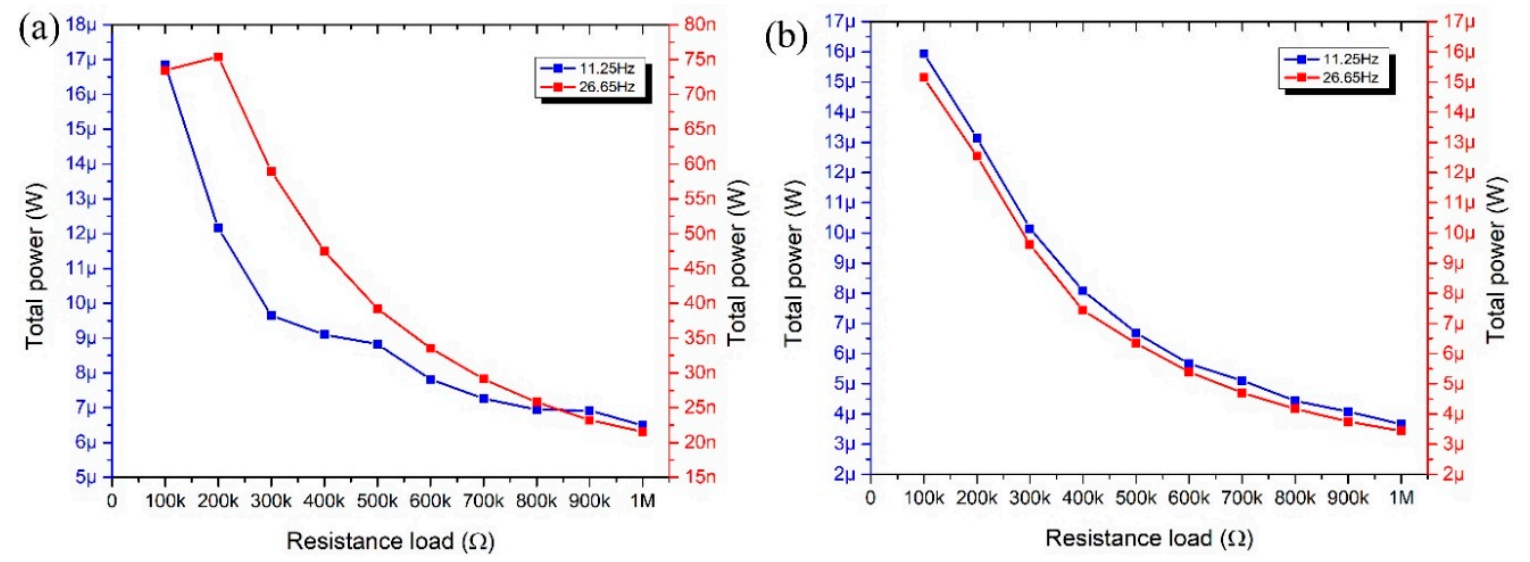

Figure 17. Measured electrical output power of bidirectional energy harvester when excitation direction is aligned with $y$ axis (a) and $z$ axis (b).

Analyzing results shown in Figure 17a, it can be noted that the maximum output power of $16.85 \mu \mathrm{W}$ was obtained at the first resonance when $100 \mathrm{k} \Omega$ resistance load was applied. The highest electrical power value of $73.45 \mathrm{nW}$ was obtained with $200 \mathrm{k} \Omega$ resistance load when harvester vibrates at the second resonant frequency. Also, it can be seen that electrical power decreases when the resistance load is increasing at both resonant frequencies.

The energy harvester produces almost the same output power characteristics at the first and second resonances when excitation direction of the harvester is aligned to $z$ axis. The highest output power was obtained at the same resistance load of $100 \mathrm{k} \Omega$ and is equal to $15.94 \mu \mathrm{W}$ and $15.14 \mu \mathrm{W}$ when energy harvester vibrates at the first and the second resonant frequency, respectively. Therefore, it can be concluded that energy harvester has better output power characteristics when excitation in the $z$ direction is applied. Moreover, energy harvester can provide much higher output power at the second resonant frequency when excitation in the $z$ direction is used.

Moreover, it can be concluded that optimal resistance load is $100 \mathrm{k} \Omega$ for the first resonant frequency and $200 \mathrm{k} \Omega$ for the second resonant frequency when excitation in the $y$ direction is applied. Optimal resistance load for the energy harvester excited in the $z$ direction is $100 \mathrm{k} \Omega$ for both resonant frequencies.

Next measurements were performed when an impact force is applied to the base of the harvester in $y$ and $z$ directions. Experimental setup with impact force sensor (Brüel \& Kjær, Denmark) was used for this purpose. Dependence of open circuit voltage and electric output power from impact force was investigated. Results are shown in Figures 18-21.

Measurements of open circuit voltage were performed from each cantilever individually as in the previous measurements. It can be seen that the first cantilever generates more than 11 times higher voltage compared to the voltage produced by the second cantilever when impact force direction is aligned to $y$ axis (Figure 18a). The maximum voltage of $8.86 \mathrm{~V}$ is obtained from the first cantilever and $0.8 \mathrm{~V}$ from the second cantilever when the impact force of $1088.11 \mathrm{~N}$ is applied. Total voltage of $9.66 \mathrm{~V}$ is generated in parallel circuit case. The highest open circuit voltage of $13.48 \mathrm{~V}$ and $6.4 \mathrm{~V}$ was generated by the first and the second cantilever, respectively when impact force of $1322.3 \mathrm{~N}$ was applied to the $z$ direction (Figure 18b). Total voltage is $19.88 \mathrm{~V}$. Also, it can be seen that open circuit voltage increases almost linearly when the impact force increasing.

Average open circuit voltage per $1 \mathrm{~N}$ was calculated when the impact force is applied to $y$ and $z$ impact directions (Figure 19). It can be seen that energy harvester generates almost the same normalized average open circuit voltage value of $0.0117 \mathrm{mV} / \mathrm{N}$ and $0.0122 \mathrm{mV} / \mathrm{N}$ in $y$ and $z$ direction. Therefore, it can be concluded that energy harvester can provide stable electrical characteristics during impact based excitation in different directions. 

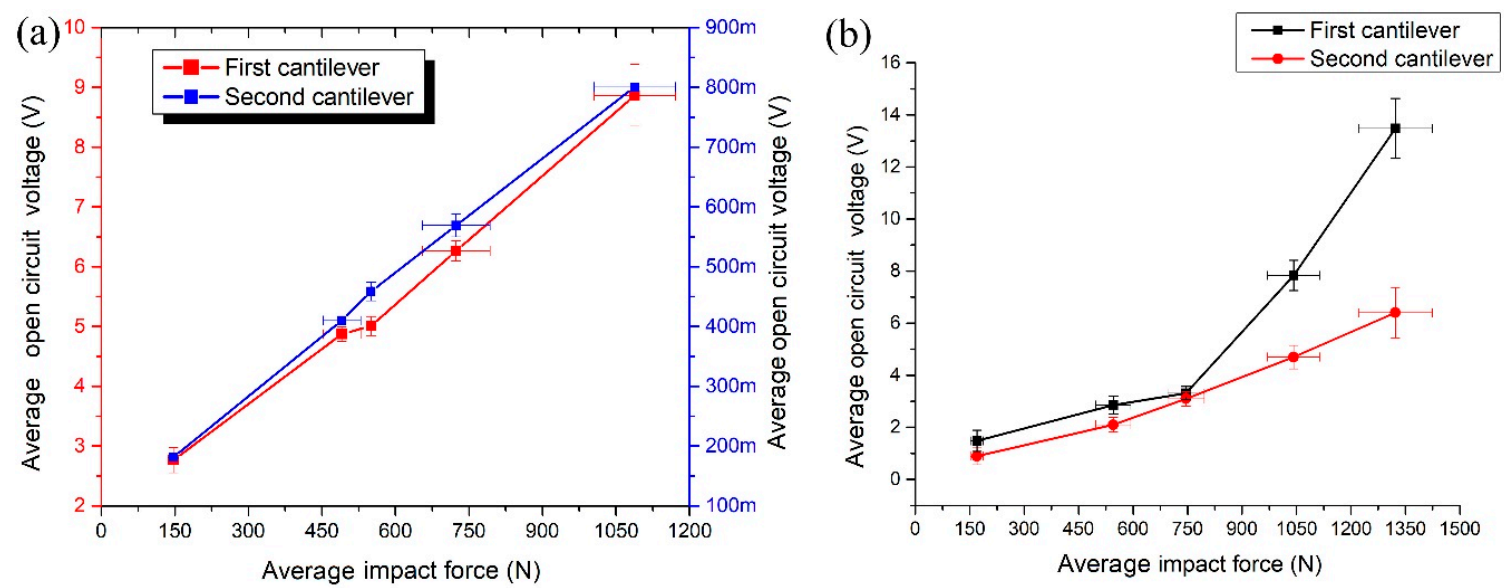

Figure 18. Measured open circuit voltage versus impact force when force direction is aligned with $y$ axis (a) and $z$ axis (b).

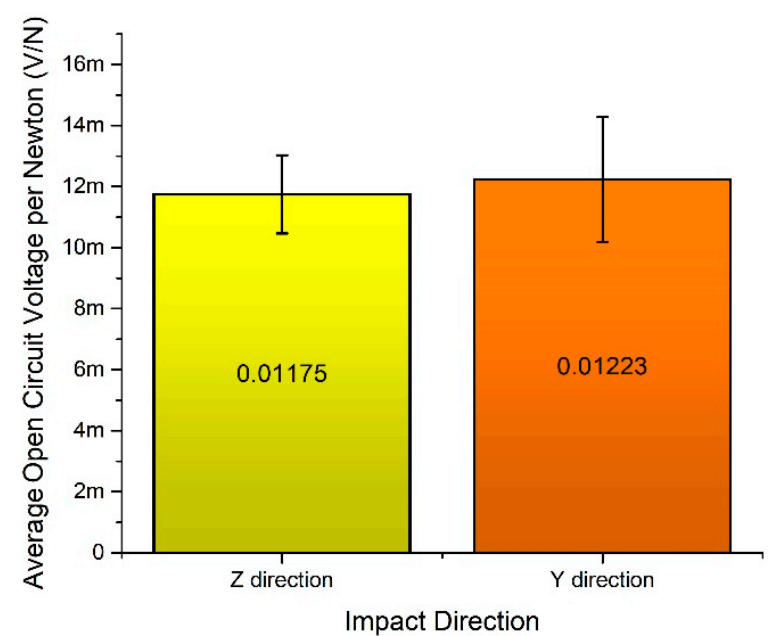

Figure 19. An average open circuit voltage per $1 \mathrm{~N}$.
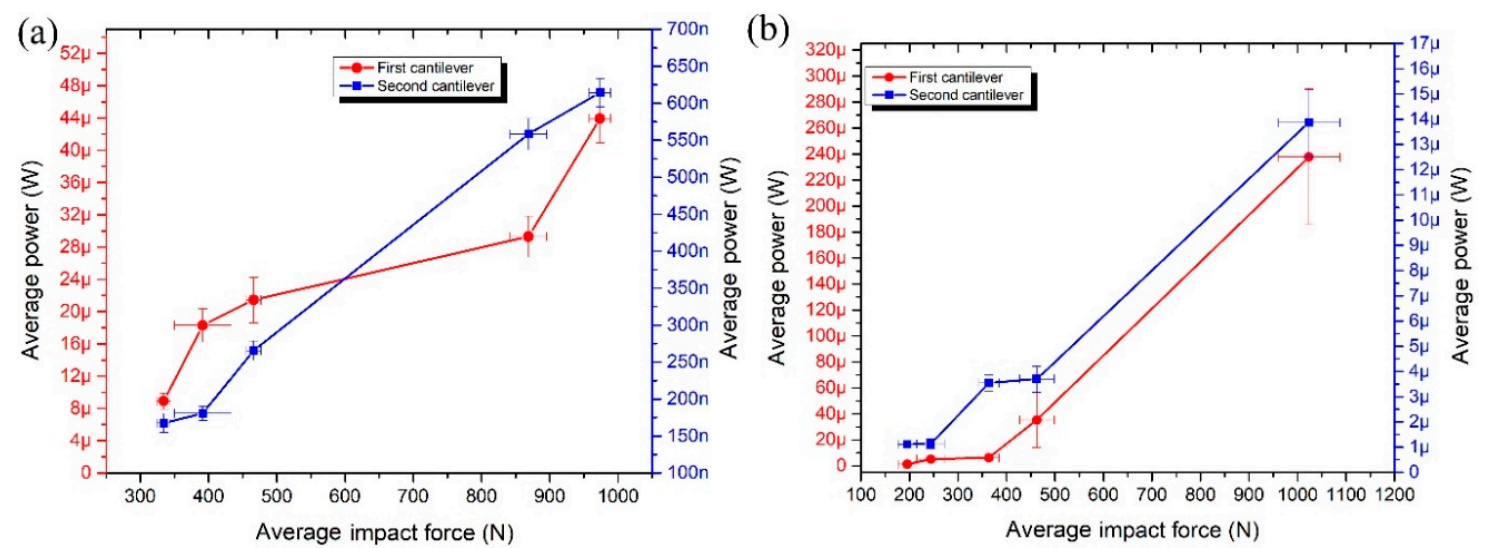

Figure 20. Measured average power versus impact force when force direction is aligned with $y$ axis (a) and $z$ axis (b).

Electric output power was measured as well when the impact force is applied in $y$ and $z$ directions (Figure 20). The highest average output power was generated by the first cantilever in both excitation cases. The electric output power of $43.93 \mu \mathrm{W}$ and $61.42 \mathrm{nW}$ was obtained from the first and the second cantilever respectively when the impact force of $973.5 \mathrm{~N}$ was applied in $y$ direction. The total maximum electric output power was $44.5 \mu \mathrm{W}$. The electric output power of $237.72 \mu \mathrm{W}$ and $13.87 \mu \mathrm{W}$ was obtained 
from the first and the second cantilever respectively when the impact force of $1023.38 \mathrm{~N}$ was applied in $z$ direction. The total maximum electric output power was $251.59 \mu \mathrm{W}$. It must be noted that the second cantilever generates more than 20 times higher power compared to power generated when the impact force is aligned to the $y$ axis.

Average electrical output power per $1 \mathrm{~N}$ was calculated when the impact force is applied to $y$ and $z$ impact directions (Figure 19). It can be seen that energy harvester generates $31.2 \mathrm{nW} / \mathrm{N}$ and $40.5 \mathrm{nW} / \mathrm{N}$ normalized electric power when the impact force is applied in $y$ and $z$ direction, respectively. The difference is $22.96 \%$.

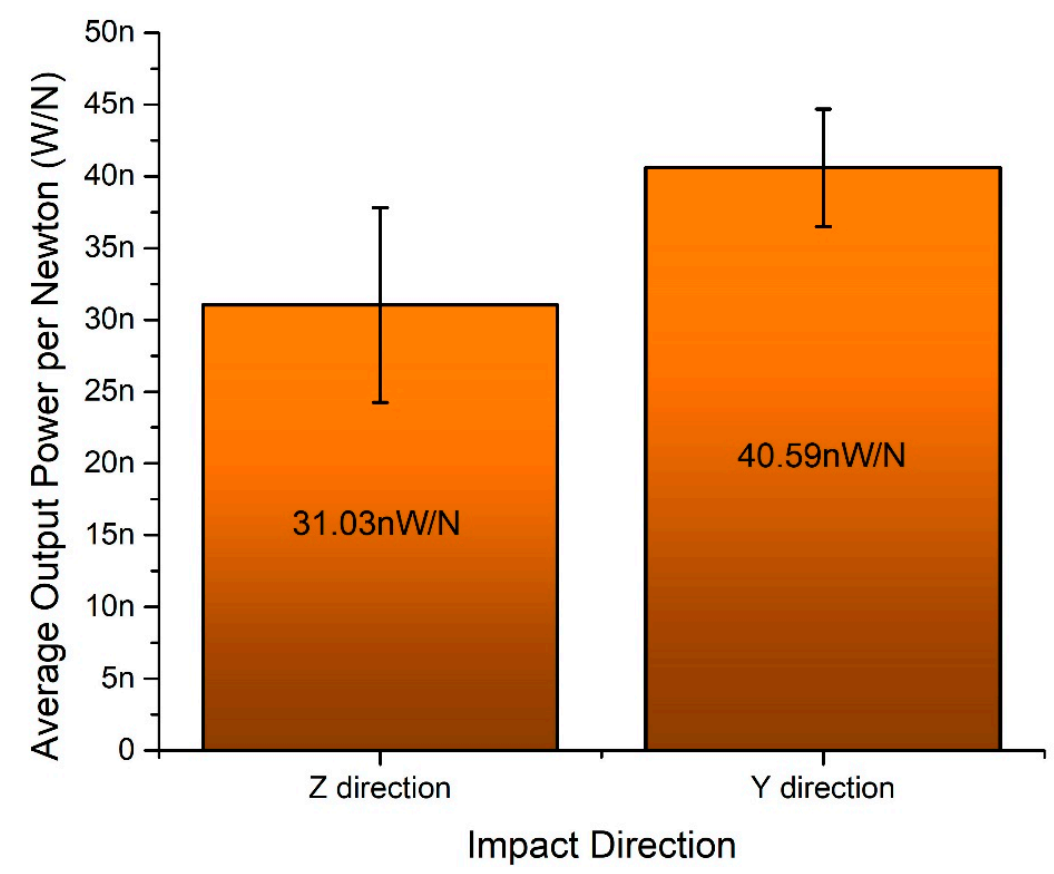

Figure 21. Characteristic of average output power per $1 \mathrm{~N}$.

\section{Conclusions}

Numerical and experimental investigations showed that the proposed design of bidirectional piezoelectric energy harvester is suitable for application when areas are filled by kinetic energy which acts in several directions. Compare to ordinary cantilever based energy harvesting systems the proposed design of energy harvester is more suitable for real-life applications. The ability to capture kinetic energy with varying force vectors makes the system more flexible for areas with complex applications problems and scopes. The bidirectional energy harvester can operate with high acceleration amplitudes and provide stable power output during harmonic excitation i.e., $16.85 \mu \mathrm{W}$ and $15.94 \mu \mathrm{W}$ in $y$ and $z$ directions, respectively. Such power level can be achieved during excitation systems operation in continuous mode. On the other hand, the energy harvester can provide $3.1 \mathrm{nW} / \mathrm{N}$ and $4.05 \mathrm{nW} / \mathrm{N}$ output power characteristics in $y$ and $z$-direction during impact based excitation. In summary, it can be concluded that the proposed design of bidirectional energy harvester eliminates demand to exact excitation force alignment to the energy harvester and provides the possibility to solve more complex energy harvesting problems in real-life applications.

Author Contributions: A.Č. contributed in conceptualization, numerical and experimental investigations, writing and preparation of manuscript. D.M. contributed in conceptualization, numerical and experimental investigations, writing and preparation of manuscript. A.K. contributed in experimental investigations and creation of experimental investigations methodology.

Funding: This project has received funding from the European Regional Development Fund (project No 01.2.2-LMT-K-718-01-0010) under a grant agreement with the Research Council of Lithuania.

Conflicts of Interest: The authors declare no conflict of interest. 


\section{References}

1. Lee, J. Nano Devices and Circuit Techniques for Low-Energy Applications and Energy Harvesting, 1st ed.; Springer Science+Business Media: London, UK, 2016.

2. Stephen, N.G. On energy harvesting from ambient vibration. J. Sound Vib. 2006, 293, 409-425. [CrossRef]

3. Todaro, M.T.; Guido, F.; Mastronardi, V.; Desmaele, D.; Epifani, G.; Algieri, L.; De Vittorio, M. Piezoelectric MEMS vibrational energy harvesters: Advances and outlook. Microelectron. Eng. 2017, 183, 23-36. [CrossRef]

4. Akhtar, F.; Rehmani, M.H. Energy replenishment using renewable and traditional energy resources for sustainable wireless sensor networks: A review. Renew. Sustain. Energy Rev. 2015, 45, 769-784. [CrossRef]

5. Beeby, S.P.; Tudor, M.J.; White, N.M. Energy harvesting vibration sources for microsystems applications. Meas. Sci. Technol. 2006, 17, R175. [CrossRef]

6. Siang, J.; Lim, M.H.; Salman Leong, M. Review of vibration-based energy harvesting technology: Mechanism and architectural approach. Int. J. Energy Res. 2018, 42, 1866-1893. [CrossRef]

7. Naifar, S.; Bradai, S.; Viehweger, C.; Kanoun, O. Survey of electromagnetic and magnetoelectric vibration energy harvesters for low frequency excitation. Measurement 2017, 106, 251-263. [CrossRef]

8. Li, X.; Xu, G.; Xia, X.; Fu, J.; Huang, L.; Zi, Y. Standardization of triboelectric nanogenerators: Progress and perspectives. Nano Energy 2019, 56, 40-55. [CrossRef]

9. Priya, S.; Song, H.; Zhou, Y.; Varghese, R.; Chopra, A.; Kim, S.; Kanno, I.; Wu, L.; Ha, D.; Ryu, J.; et al. A Review on Piezoelectric Energy Harvesting: Materials, Methods, and Circuits. Energy Harvest. Syst. 2017, 4, 3-39. [CrossRef]

10. Yildirim, T.; Ghayesh, M.H.; Li, W.; Alici, G. A review on performance enhancement techniques for ambient vibration energy harvesters. Renew. Sustain. Energy Rev. 2017, 71, 435-449. [CrossRef]

11. Viswanath, A.K.; Srikanth, K. State of art: Piezoelectric Vibration Energy Harvesters. Mater. Today Proc. 2017, 4, 1091-1098.

12. Dagdeviren, C.; Joe, P.; Tuzman, O.L.; Park, K.I.; Lee, K.J.; Shi, Y.; Huang, Y.; Rogers, J.A. Recent progress in flexible and stretchable piezoelectric devices for mechanical energy harvesting, sensing and actuation. Extrem Mech. Lett. 2016, 9, 269-281. [CrossRef]

13. Jia, Y.; Seshia, A.A. Five topologies of cantilever-based MEMS piezoelectric vibration energy harvesters: A numerical and experimental comparison. Microsyst. Technol. 2016, 22, 2841-2852. [CrossRef]

14. Fan, K.; Chang, J.; Chao, F.; Pedrycz, W. Design and development of a multipurpose piezoelectric energy harvester. Energy Convers. Manag. 2015, 96, 430-439. [CrossRef]

15. Mei, J.; Li, L. Double-wall piezoelectric cylindrical energy harvester. Sens. Actuators A Phys. 2015, 233, 405-413. [CrossRef]

16. Yang, Y.; Wu, H.; Soh, C.K. Experiment and modeling of a two-dimensional piezoelectric energy harvester. Smart Mater. Struct. 2015, 24, 125011. [CrossRef]

17. Wang, P.; Liu, X.; Zhao, H.; Zhang, W.; Zhang, X.; Zhong, Y.; Guo, Y. A two-dimensional energy harvester with radially distributed piezoelectric array for vibration with arbitrary in-plane directions. J. Intell. Mater. Syst. Struct. 2019, 30, 1094-1104. [CrossRef]

18. Karami, M.A.; Inman, D.J. Parametric study of zigzag microstructure for vibrational energy harvesting. J. Microelectromech. Syst. 2012, 21, 145-160. [CrossRef]

19. Karami, M.A.; Inman, D.J. Electromechanical modeling of the low-frequency zigzag micro-energy harvester. J. Intell. Mater. Syst. Struct. 2011, 22, 271-282. [CrossRef]

20. Doria, A.; Medè, C.; Fanti, G.; Desideri, D.; Maschio, A.; Moro, F. Development of Piezoelectric Harvesters with Integrated Trimming Devices. Appl. Sci. 2018, 8, 557. [CrossRef]

21. Yuan, M.; Liu, K.; Sadhu, A. Simultaneous vibration suppression and energy harvesting with a non-traditional vibration absorber. J. Intell. Mater. Syst. Struct. 2018, 29, 1748-1763. [CrossRef]

22. Huang, S.C.; Nguyen, L.H.; Liang, J.W.; Huang, Y.M. Design and analysis of a collocated periodic vibration absorber-harvester. Int. J. Mech. Sci. 2018, 148, 337-351. [CrossRef]

(C) 2019 by the authors. Licensee MDPI, Basel, Switzerland. This article is an open access article distributed under the terms and conditions of the Creative Commons Attribution (CC BY) license (http://creativecommons.org/licenses/by/4.0/). 